\title{
The Effect of Foundation Flexibility on Probabilistic Seismic Performance of Plan-Asymmetric Buildings with Different Strength Distributions
}

\author{
Sahar Mohammadzadeh Osalu and Hamzeh Shakib \\ Department of Civil and Environmental Engineering, Tarbiat Modares University, Tehran, Iran \\ Correspondence should be addressed to Hamzeh Shakib; shakib@modares.ac.ir
}

Received 31 January 2020; Revised 22 June 2020; Accepted 14 July 2020; Published 5 August 2020

Academic Editor: Giovanni Minafò

Copyright ( $\odot 2020$ Sahar Mohammadzadeh Osalu and Hamzeh Shakib. This is an open access article distributed under the Creative Commons Attribution License, which permits unrestricted use, distribution, and reproduction in any medium, provided the original work is properly cited.

\begin{abstract}
In this research, the probabilistic seismic performance of asymmetric reinforced concrete wall-frame buildings with different strength distributions incorporating foundation flexibility effects is examined. By using probability-based performance evaluation approach, it is possible to provide a more accurate prediction of the different strength distribution effect on the seismic performance of asymmetric buildings and find the most efficient strength distribution for meeting each performance level. These efficient distributions can be adopted in the performance-based design of asymmetric buildings. For this purpose, first, the regression analysis and the concepts of efficiency and sufficiency were used to determine an optimal intensity measure (IM) for incremental dynamic analysis and evaluating the seismic response of the considered building models. Then, the proper magnitude of interstory drift capacity for this type of buildings in each limit state was estimated using the damage index concept. Finally, the effects of different strength distributions and the flexibility of foundation were studied on the seismic performance of the asymmetric buildings by investigating the mean annual frequencies of exceeding structural performance levels and confidence levels to satisfy performance objectives. It is concluded that irregular distributions of stiffness and strength in the plan of a building highly affect the seismic performance of buildings. Also, the results show that the optimum strength distribution is a function of the objective performance level and these optimum strength distributions are the same for both fixed- and flexible-base conditions. Meanwhile, the flexible effect of foundation increases the mean annual frequencies of exceedance within the range of $10 \%$ to $45 \%$ and significantly decreases the confidence levels in most cases.
\end{abstract}

\section{Introduction}

The experience of past earthquakes has demonstrated that asymmetric buildings are more vulnerable to intensive earthquakes compared to symmetric buildings. Irregular distributions of stiffness and strength among the lateral force-resisting elements (LFREs) of a building can result in coupled lateral-torsional dynamic response which is the main cause of extensive damages in asymmetric buildings $[1,2]$. So far, there have been two different concepts for distribution of strength and stiffness among the LFREs of the buildings. Earlier studies traditionally assumed that the stiffness of an element is an independent parameter and can be estimated based on its geometric characteristics.
However, in recent years, it has been pointed out that for many commonly used LFREs such as concrete momentresisting frames and shear walls, stiffness is a strength-dependent parameter and will be calculated after the strength allocation among the LFREs [3-5]. These two different types of LFREs are called K-type [6] and D-type [7] elements, respectively.

In D-type elements, the yield displacement is independent of stiffness and strength and can be estimated based on the geometry and material properties. Therefore, it can be said that stiffness and strength of a D-type element depend on its yield displacement, and both stiffness and strength eccentricities are important parameters that affect the seismic response of structures [5]. Paulay [8] was the first to 
study the seismic behavior of asymmetric buildings composed of elements having strength-dependent stiffness, and he claimed that the common lateral strength allocation specified in modern seismic building codes is not rational. Tso and Myslimaj [9, 10] proposed a yield displacement distribution-based approach for strength allocation to D-type LFREs which does not need the information of stiffness distribution prior to the strength allocation. They used a single-story wall-type model and investigated the effects of different arrangements of centers of stiffness (CS) and strength (CR) with respect to the center of mass (CM) on the diaphragm rotation response of the model. They concluded that the optimal arrangement of the centers is one where the centers of strength and stiffness are located on opposite sides of the mass center. This configuration is known as "balanced CS-CR location" in the literature. The authors also demonstrated that there is a noticeable change in the trend of the diaphragm rotation at different seismic input levels. At lower earthquake levels, the minimum rotations are obtained in the models with minimum stiffness eccentricity, but there is a shift towards minimum strength eccentricity as the seismic input level increases [9]. Shakib and Ghasemi [11] studied the effects of near-fault and farfault ground motions on structural responses of asymmetric buildings supported by wall elements. Their results indicated that considering D-type elements, in near-fault ground motions, the balanced configuration of the stiffness and strength centers leads to the minimum rotational response. Aziminejad and Moghadam [12, 13] studied the performance of wall-type asymmetric buildings by using nonlinear dynamic analyses. The results were presented in the form of different limit-state fragility curves. They concluded that for interstory drift responses, models with balanced configuration and strength eccentricity equal to 0.25 of the distance between CR and CS perform better. However, in general, the proper configuration of centers differs significantly depending on the selected engineering demand parameter.

Most of the above studies were carried out by employing simple models with shear wall systems, while in most real systems the frames are also involved in lateral-load resistance. For this reason, in this study, the seismic performance of plan-asymmetric reinforced concrete buildings with shear wall-frame system has been evaluated. In addition, since there is no general agreement on the optimal configuration of the various centers, an attempt was made to quantify the effects of different strength distributions on the seismic performance of structures and identify a more reliable configuration of centers in each limit state by using a probabilistic performance assessment approach.

On the other hand, the global seismic behavior of a specific structure may be totally different when it is founded on flexible soil compared to a fixed base. This difference is mainly due to the soil-structure interaction (SSI) phenomenon. Several researchers have so far attempted to incorporate the effects of the foundation flexibility on asymmetric buildings [14-16]. Shakib and Fuladgar [17] studied the seismic response of asymmetric structures composed of K-type elements with soil flexibility. They concluded that SSI effects reduce the lateral and torsional responses of asymmetric buildings. However, as the structural period is increased, the effect of base flexibility is noticeably decreased. They also found that the eccentricity ratio of the asymmetric system has a significant effect on the response of soil-structure interaction. Roy and Chandra Dutta [18] studied the inelastic seismic demand of low-rise asymmetric buildings with soil flexibility and assuming that the stiffness is independent of the strength in the LFREs of the structural models. They concluded that the nonlinear behavior of the asymmetric system compared to the reference symmetric model is not extremely affected by SSI. However, the effect of soil-structure interaction on the nonlinear range of structural behavior may result in increased damages. Shakib and Atefatdoost [19] performed nonlinear analysis of three-dimensional dynamic soilstructure interaction of asymmetric buildings with D-type walls. Their results showed that with increasing base flexibility, the slab rotation of asymmetric buildings decreases, and the minimum slab rotation occurs when CS and CR are on the opposite sides of CM (balanced condition). More recently, Atefatdoost et al. [20] studied the effect of SSI on the seismic response of idealized single-story asymmetric buildings subject to near-fault pulse-like earthquakes. They concluded that for flexible-base structures, the reduction in the base shear results only in the center of stiffness to control torsional response; meanwhile, for structures with fixed base, both centers of stiffness and strength are controlling.

In the literature, there is no study investigating base flexibility effects on asymmetric buildings from the standpoint of probabilistic performance-based earthquake engineering. Therefore, this study has provided an opportunity to examine the influence of soil-foundation flexibility on the seismic behavior, in addition to strength distribution effects by implementing incremental dynamic analysis (IDA) and reliability-based probabilistic approach. For this purpose, first, the efficiency and sufficiency of different intensity measures (IMs) for evaluating the seismic response of the models were investigated and an optimal IM was chosen for performance assessment. Then, the proper magnitude of interstory drift capacity for RC wall-frame buildings in each limit state was estimated using the damage index concept. Finally, the effect of different strength distributions was studied on the probabilistic performance of asymmetric buildings in fixed-and flexible-base conditions by evaluating the mean annual frequencies of exceedance and confidence levels to satisfy performance objectives.

\section{Characteristics of Wall-Frame Buildings with D-Type Elements}

For studying the seismic behavior of wall-frame buildings with D-type elements, first, the yield displacements of the elements should be calculated. As previously mentioned, research concerning the concrete moment-resisting frames and shear walls has pointed out that the yield displacement of these LFREs depends only on their geometric characteristic and the properties of the material used and is essentially independent of their strength $[3,5]$. The yield displacement of a cantilever shear wall, $\Delta_{y w}$, as 
recommended by Paulay [3], can be obtained from the following equation:

$$
\Delta_{y w}=\frac{C \varepsilon_{y} h^{2}}{l_{w}}
$$

in which $\varepsilon_{y}$ is the steel reinforcement yield strain, $l_{w}$ is the wall thickness, $h$ is its height, and $C$ is a coefficient which quantifies the lateral force distribution pattern. For example, for shear walls with lateral force applying at the top, $C$ is equal to 0.66 [3].

Also, for a concrete moment-resisting frame, the following equation can be used to estimate the yield displacement at roof level [5]:

$$
\Delta_{y f}=0.5 \varepsilon_{y} \frac{L_{b}}{D_{b}} h,
$$

where $L_{b}$ and $D_{b}$ are the length and depth of the beam, respectively.

According to Reference [3], within reasonable limits, the strength of the elements may be assigned arbitrarily, and so the designer has also the freedom to choose the fractions of base shear force carried by the wall and the frame in wallframe buildings. This arbitrariness can make it possible for the designer to choose the more rational and economical design solution from a number of possible solutions [21]. After calculating the yield displacement of each element, $\Delta_{y i}$, and assigning its strength, $V_{i}$, its stiffness $\left(K_{i}\right)$ can be estimated by the following equation:

$$
K_{i}=\frac{V_{i}}{\Delta_{y i}} .
$$

The global yield displacement of the wall-frame system, $\Delta_{y}$, can also be obtained from

$$
\Delta_{y}=\frac{V_{t}}{\left(V_{w} / \Delta_{y w}\right)+\left(V_{f} / \Delta_{y f}\right)},
$$

where $V_{w}$ and $V_{f}$ are the wall and frame strengths, respectively.

\section{Numerical Modeling}

3.1. Structural System. A single-story RC wall-frame system is considered in this study as a reference symmetric model, Model 1 (Figure 1). This model consists of a rigid deck of plan dimensions $12 \mathrm{~m} \times 8 \mathrm{~m}$ that is supported by two reinforced concrete walls and two moment-resisting frames in $y$-direction, and two walls and four moment-resisting frames in $x$-direction, as shown in the figure. The story height is considered equal to $3 \mathrm{~m}$. The model is assumed to be located on a site with very high seismicity and a sitespecific earthquake acceleration of $0.35 \mathrm{~g}$ (Tehran, Iran) according to the Iranian Seismic Design Code [22]. The design gravity load of the model is 150 tonf, and the design base shear, which has been calculated based on Reference [22], is equal to 24 tonf. According to the definition of dual wall-frame buildings in this code, the total base shear has been distributed between walls and moment frames with the ratio 3 to 1 in each direction. All walls have a length of $2 \mathrm{~m}$

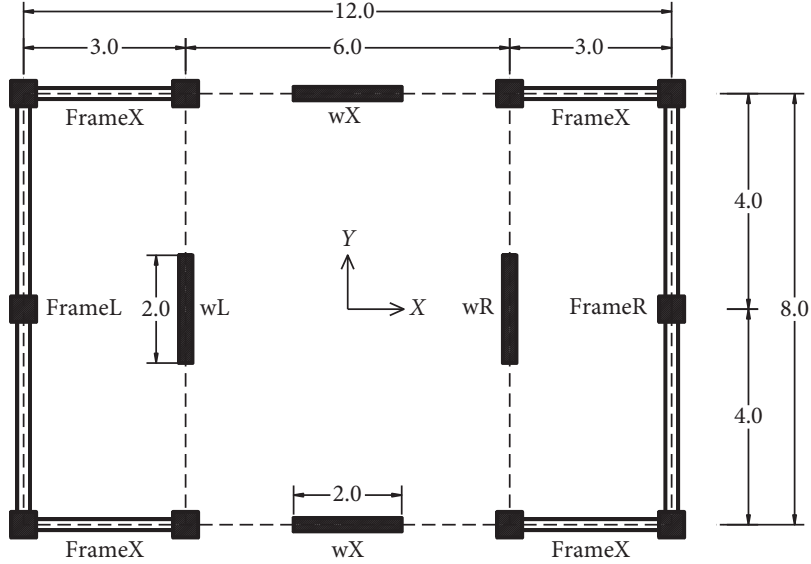

FIgURE 1: Arrangement of resisting elements in the plan.

and a thickness of $0.25 \mathrm{~m}$ with two layers of distributed reinforcement, $\varphi 16 @ 150 \mathrm{~mm}$. Also, the same cross section of $0.3 \times 0.3 \mathrm{~m}^{2}$ is considered for all beams and columns with $1.5 \%$ and $2.5 \%$ reinforcement ratios, respectively. A concrete compressive strength of $21 \mathrm{MPa}$ and a yield strength of $300 \mathrm{MPa}$ are assumed for concrete and steel reinforcement, respectively.

The total lateral strengths of all asymmetric models considered in the study (Models 2 to 10) along both directions are assumed to be equal to that of the symmetric model. In order to prepare the asymmetric models, the dimensions of the cross sections and the yield strain of reinforcements in the left and right side elements in the $y$ direction are changed so that the normalized distance between the yield displacement center (CD) and the mass center (CM) of the models becomes equal to $15 \%$ $\left(e_{D}=15 \%\right)$. To create strength eccentricity, a yield displacement distribution-based approach has been used as suggested by Tso and Myslimaj [9]. Based on this approach, the strength assignment is accomplished by the following two conditions: (a) the strength eccentricity, $e_{r}$, is considered linearly proportional to the yield displacement eccentricity, $e_{D}$, by the relation " $e_{r}=\beta e_{D}$," where $\beta$ is a variable parameter that is selected by the designer; and (b) the radius of gyration for strength distribution is equal to that for the yield displacement distribution. After distributing the strength among the elements, the stiffness of each element can be calculated by equation (3). The general properties of the structural models are presented in Table 1 . In this table, $e_{s}$ is the stiffness eccentricity, also expressed as a percentage of the plan length dimension, like $e_{D}$ and $e_{r} . T_{1}, T_{2}$, and $T_{3}$ represent the first three modal periods (two sway modes and one torsional mode), and $\omega_{y}$ and $\omega_{\theta}$ define the lateral sway (corresponding to $T_{1}$ ) and torsional (corresponding to $T_{3}$ ) frequencies of the structural models, respectively. The torsional to the lateral frequency ratio $(\Omega)$ indicates that all considered models are torsionally stiff $(\Omega>1)$. To better clarify the dynamic behavior of the models, the modal mass participation factors for the sway mode in $y$-direction $\left(\mathrm{MPF}_{y y}\right.$ and $\left.\mathrm{MPF}_{y \theta}\right)$ and the torsional mode $\left(\mathrm{MPF}_{\theta y}\right.$ and $\left.\mathrm{MPF}_{\theta \theta}\right)$ are also shown in Table 1 . It is clear that by reducing 
TAвLE 1: General properties of the building models.

\begin{tabular}{|c|c|c|c|c|c|c|c|c|c|c|c|}
\hline \multirow[t]{2}{*}{ Model no. } & \multirow[t]{2}{*}{$\beta$} & \multirow[t]{2}{*}{$e_{D}(\%)$} & \multirow[t]{2}{*}{$e_{r}(\%)$} & \multirow{2}{*}{$e_{s}(\%)$} & \multirow{2}{*}{$T_{1}(\mathrm{~s})$} & \multirow{2}{*}{$T_{2}(\mathrm{~s})$} & \multirow{2}{*}{$T_{3}(\mathrm{~s})$} & \multirow{2}{*}{$\omega_{y}(\mathrm{rad} / \mathrm{s})$} & \multirow{2}{*}{$\omega_{\theta}(\mathrm{rad} / \mathrm{s})$} & \multicolumn{2}{|c|}{$\begin{array}{c}\text { Modal mass participation factors } \\
(\mathrm{MPF})(\%)\end{array}$} \\
\hline & & & & & & & & & & $\mathrm{MPF}_{y y}=\mathrm{MPF}_{\theta \theta}$ & $\mathrm{MPF}_{y \theta}=\mathrm{MPF}_{\theta y}$ \\
\hline 1 & Sym. & 0.0 & 0.0 & 0.0 & 0.379 & 0.379 & 0.287 & 16.58 & 21.89 & 100 & 0 \\
\hline 2 & -1.0 & 15.0 & -15.6 & -20.9 & 0.407 & 0.379 & 0.256 & 15.43 & 24.54 & 61.36 & 38.64 \\
\hline 3 & -0.75 & 15.0 & -11.7 & -19.3 & 0.398 & 0.379 & 0.258 & 15.79 & 24.35 & 63.60 & 36.40 \\
\hline 4 & -0.5 & 15.0 & -7.8 & -17.5 & 0.396 & 0.379 & 0.265 & 15.87 & 23.71 & 66.79 & 33.21 \\
\hline 5 & -0.25 & 15.0 & -3.9 & -15.4 & 0.393 & 0.379 & 0.269 & 15.99 & 23.36 & 70.72 & 29.28 \\
\hline 6 & 0.0 & 15.0 & 0.0 & -13.1 & 0.391 & 0.379 & 0.274 & 16.06 & 22.93 & 75.83 & 24.17 \\
\hline 7 & 0.25 & 15.0 & 3.9 & -10.5 & 0.387 & 0.379 & 0.278 & 16.24 & 22.6 & 82.38 & 17.62 \\
\hline 8 & 0.5 & 15.0 & 7.8 & -7.5 & 0.385 & 0.379 & 0.282 & 16.32 & 22.28 & 90.11 & 9.89 \\
\hline 9 & 0.75 & 15.0 & 11.7 & -4.0 & 0.382 & 0.379 & 0.285 & 16.45 & 22.04 & 97.13 & 2.87 \\
\hline 10 & 1.0 & 15.0 & 15.6 & 0.0 & 0.379 & 0.379 & 0.287 & 16.58 & 21.89 & 100 & 0 \\
\hline
\end{tabular}

the parameter $\beta$ from 1.0 to -1.0 , the correlation between the lateral and torsional components of displacements increases, consequently, the ratios of $\mathrm{MPF}_{y \theta}$ and $\mathrm{MPF}_{\theta y}$ increase, and the corresponding values for $\mathrm{MPF}_{y y}$ and $\mathrm{MPF}_{\theta \theta}$ decrease. The mass center of all models has been considered at the geometric center of the rigid diaphragm.

Dynamic nonlinear analyses of the models were performed by OpenSees software [23]. The damping ratio of the models was assumed 5\%, and Rayleigh mass and stiffness proportional damping was considered for damping properties [24]. The peak-oriented hysteretic model, proposed by Ibarra et al. [25], was used for nonlinear modeling of the elements. Based on this model, nonlinear behavior of beams and columns is modeled by a linear middle part and two lumped plastic hinges at the end of elements, and nonlinear model of walls is composed of a linear part and one plastic hinge at the base [26]. It should be noted that this model considers all degradation modes including the basic and postcapping strength and the loading and accelerated unloading stiffness degradation effects in the cyclic response. A typical backbone curve of the model is shown in Figure 2. In this figure, $M_{y}$ and $M_{c}$ represent the yielding and capping moment capacities which can be calculated based on the lateral strength assigned to the element. $\theta_{y}, \theta_{p}$, and $\theta_{p c}$ are the yielding, plastic, and postcapping rotation capacities for the lumped plastic hinges, respectively. In this study, the values of rotation capacities for shear walls and frame elements were adopted from Krawinkler and Zareian [26]. Based on this reference, $\theta_{y}$ can be calculated using the geometric and mechanical characteristic of the element. For moment-resisting frames, the parameters $\theta_{p}$ and $\theta_{p c}$ are taken equal to 0.03 and 0.15 , respectively, and for shear walls, the corresponding parameters are assumed to be 0.02 .

3.2. Foundation System. In this study, according to the Iranian Seismic Design Code site classification [22], the underlying soil is assumed to be of Type III $\left(175(\mathrm{~m} / \mathrm{s})<V_{s 30}<375(\mathrm{~m} / \mathrm{s})\right)$ which is equivalent to Soil Class D of ASCE 41-13 [27]. The properties of sandy soil material considered for this study are listed in Table 2 . The Iranian Foundation Design Code [28] was used for the design of strip foundations. Based on this code, the safety

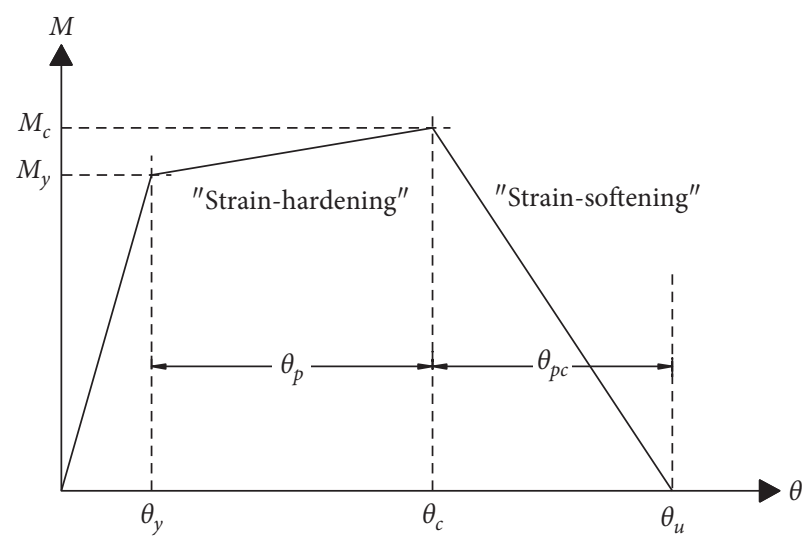

FIGURE 2: Monotonic backbone curve for reinforced concrete elements.

factors of 3.0 and 1.5 were considered against the bearing and sliding capacity failure of the foundations, respectively. Figure 3 shows the arrangement and the dimensions of strip footing elements considered in this study. As it is seen in the figure, the adjacent footing elements were connected to each other to enforce harmonized motions during the seismic excitations.

The well-known theory of beam on nonlinear Winkler foundation (BNWF) was utilized for modeling the flexibility of the foundation, as used in several studies [29-38]. The simplicity and capability of the BNWF model in accounting for nonlinear behavior of shallow foundations are its two main beneficial features. This model includes elastic beam elements to model the footing of the structure and linear/ nonlinear zero-length springs to capture the soil material behavior [30]. The arrangement of these zero-length springs is schematically shown in Figure 4(a). The horizontal springs are known as $\mathrm{t}-\mathrm{x}$ and $\mathrm{p}-\mathrm{x}$ springs which capture sliding and passive resistance of the foundation in horizontal movements, respectively. The vertical springs, called $\mathrm{q}-\mathrm{z}$ springs, are used to simulate footing uplift and compression yielding in the soil medium. The nonlinear backbone curves of these three different sets of springs are shown in Figures 4(b)4(d). The expressions describing the backbone curves of the springs are similar and have been originally mentioned in Reference [38]. 
TABLE 2: Values of the soil modeling parameters.

\begin{tabular}{lcccccc}
\hline Soil type & $\begin{array}{c}\text { Shear wave velocity } \\
V_{s 30}(\mathrm{~m} / \mathrm{s})\end{array}$ & $\begin{array}{c}\text { Cohesion } \\
C(\mathrm{MPa})\end{array}$ & $\begin{array}{c}\text { Friction angle } \\
\varphi^{\circ}\end{array}$ & $\begin{array}{c}\text { Poisson's ratio } \\
v\end{array}$ & $\begin{array}{c}\text { Mass density } \\
\rho\left(\mathrm{kg} / \mathrm{m}^{3}\right)\end{array}$ & $\begin{array}{c}\text { Initial shear modulus } \\
G_{0}(\mathrm{MPa})\end{array}$ \\
\hline $\mathrm{D}$ & 250 & 0 & 35 & 0.3 & 1800 & 115 \\
\hline
\end{tabular}

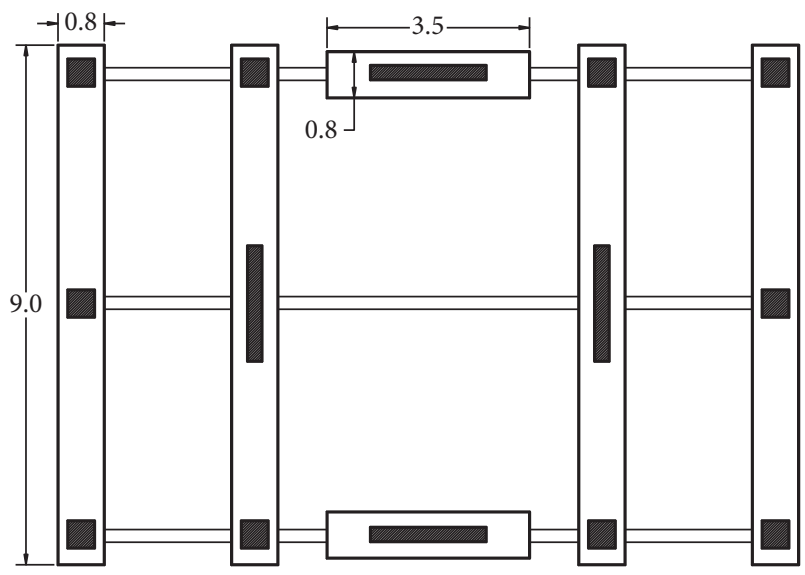

Figure 3: Plan of foundations.

As shown in Figures 4(b)-4(d), each backbone curve has two parts. In the elastic part of the backbone curve, a linear load-displacement equation is considered, in which $k_{i n}$ shows the initial elastic stiffness:

$$
F=k_{\text {in }} \delta
$$

According to Reference [27], the initial elastic stiffness of soil springs depends on the rigidity and bending stiffness of the foundation. Strip foundations can be considered rigid when

$$
\frac{E I}{L^{4}}>\frac{2}{3} k_{s v} B ; \quad k_{s v}=\frac{1.3 G}{B(1-v)} .
$$

In this equation, $B$ and $L$ are the width and length of the footing, respectively, $E$ is the elastic modulus of the footing material (concrete), $v$ is Poisson's ratio of soil, $I$ is the second moment of area of the footing section, and $G$ is the shear modulus of the soil material. Note that $G$ is expected to decline at large strains due to increasing seismic input levels; this effect can be considered in the modeling by using effective shear modulus ratios. Table 3 summarizes the values of shear modulus ratios recommended by ASCE 41-13 [27] for soil type D.

After determining the rigidity of the foundation, the vertical spring coefficient of the foundation can be calculated using the following equation [27]:

$$
k_{z}= \begin{cases}\frac{G B}{1-v}\left[1.55\left(\frac{L}{B}\right)^{0.75}+0.8\right], & \text { for a rigid foundation, } \\ \frac{1.3 G}{B(1-v)}, & \text { for a flexible foundation. }\end{cases}
$$

Generally, the horizontal spring coefficients for both rigid and flexible foundations are expressed as

$$
\begin{aligned}
& k_{x}=\frac{G B}{2-v}\left[3.4\left(\frac{L}{B}\right)^{0.65}+1.2\right] \\
& k_{y}=\frac{G B}{2-v}\left[3.4\left(\frac{L}{B}\right)^{0.65}+0.4 \frac{L}{B}+0.8\right] .
\end{aligned}
$$

In the nonlinear part, the backbone curve is defined by

$$
F=F_{\text {ult }}-\left(F_{\text {ult }}-F_{0}\right)\left[\frac{c \delta_{50}}{c \delta_{50}+\left|\delta-\delta_{0}\right|}\right]^{n}
$$

In this equation, $F_{\text {ult }}$ and $F_{0}$ are the ultimate and the yielding capacities, respectively, $\delta_{50}$ is the displacement where $50 \%$ of $F_{\text {ult }}$ is mobilized, $\delta_{0}$ is the displacement corresponding to the yielding pressure, and $c$ and $n$ are constants that control the shape of the nonlinear part of the curve. Raychowdhury and Hutchinson [31] calibrated these two constants from shallow footing tests, and some relations were suggested by Harden et al. [32] for determination of $\delta_{50}$ for each set of springs, which were also used in the current study.

For modeling of the soil material properties, the QzSimple1 (Figure 4(b)), PxSimple1 (Figure 4(c)), and TxSimple1 (Figure 4(d)) material models were employed from OpenSees, and the spring elements were distributed along the footings' length according to the recommendation by Harden et al. [32].

3.3. Ground Motions. A total number of 20 two-directional ground motions described in Table 4 have been used in this study, selected from the Ground Motion Database of the Pacific Earthquake Engineering Research Center [39]. All ground motion records were recorded on soil type D $\left(175(\mathrm{~m} / \mathrm{s})<V_{s 30}<375(\mathrm{~m} / \mathrm{s})\right)$ with large magnitudes $(6.0<M<7.5)$, and the closest distance to the fault rupture $(R)$ was considered larger than $10 \mathrm{~km}$ with no marks of directivity effects.

\section{Incremental Dynamic Analysis}

The effects of different strength distributions and soilstructure interaction on the performance of the structural models were examined by using the incremental dynamic analysis (IDA) method. This method is considered as one of the most efficient parametric analysis methods that can accurately predict the complete range of the structural response [40]. In the IDA method, the ground motion intensity measure (IM) is employed as a connector between seismicity properties and structural seismic analysis and the seismic response of the structure is characterized by the engineering demand parameter (EDP), as an observable indicator. The most common EDP for structural buildings is 


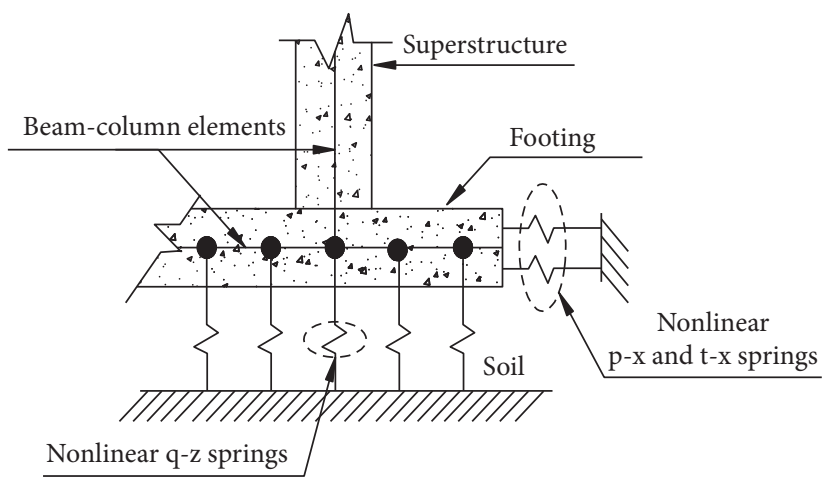

(a)

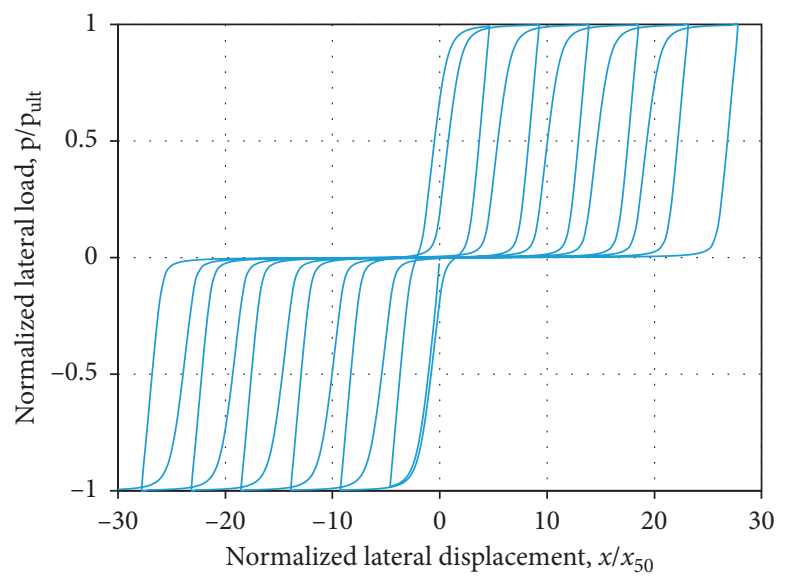

(c)

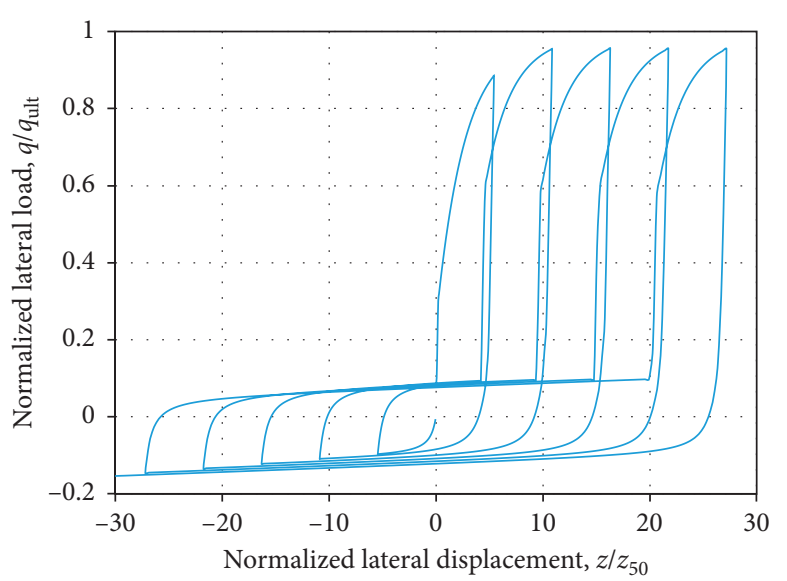

(b)

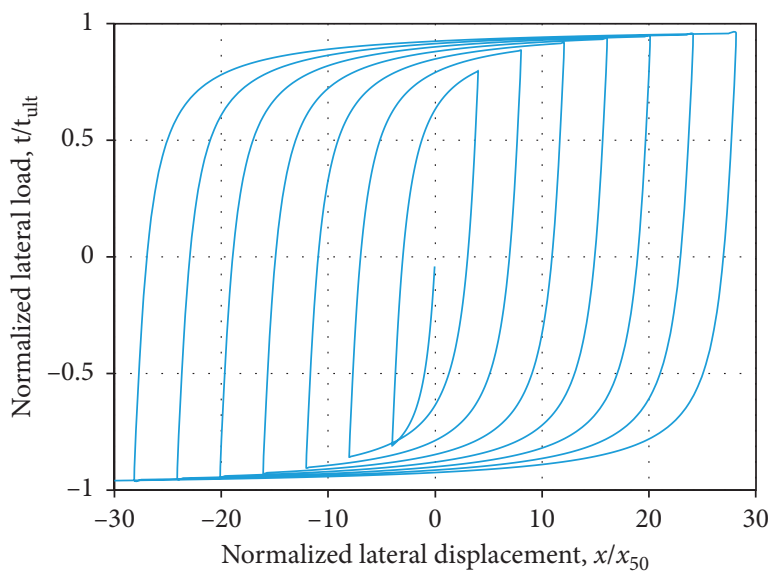

(d)

Figure 4: (a) BNWF model; (b) q-z spring behavior; (c) p-x spring behavior; (d) t-x spring behavior.

TABLE 3: Effective shear modulus ratio $\left(G / G_{0}\right)$ [27].

\begin{tabular}{lcccc}
\hline \multirow{2}{*}{ Soil type } & \multicolumn{4}{c}{ Effective peak ground acceleration $(\mathrm{g})$} \\
& 0 & 0.1 & 0.4 & 0.8 \\
\hline $\mathrm{D}$ & 1.0 & 0.9 & 0.5 & 0.1 \\
\hline
\end{tabular}

the maximum interstory drift ratio $\left(\theta_{\max }\right)$. The interstory drift capacities at different performance levels for typical lateral-load resisting systems of buildings have been defined in different seismic codes [27, 41-43]. However, there is no reference provided for interstory drift capacities for wallframe buildings. In this section, a suitable IM is determined for the considered structural models by using regression analysis and the concepts of efficiency and sufficiency. Then, an attempt was made to estimate interstory drift capacities of wall-frame buildings in different limit states.

4.1. The Optimal Intensity Measure. As mentioned at the beginning of this section, an IM serves as an interface parameter between seismic hazard and structural seismic analysis and this implies that to have a more accurate prediction of the structural demand, the correlation between
EDPs and the selected IM is highly important in performance-based earthquake engineering. According to Reference [44], the required characteristics for selecting an appropriate IM are efficiency and sufficiency. An efficient IM leads to a relatively small variability of EDP given IM and consequently a small number of ground motion records and dynamic analyses to evaluate the probability of exceedance of an EDP given IM [44]. On the other hand, a sufficient IM is defined as one that results in an EDP that is conditionally independent of earthquake magnitude $(M)$ and source-tosite distance $(R)$ [44]. Using a sufficient IM is favorable because it neutralizes the effects of magnitude and source distance on the estimation of EDP [44]. Many studies are reported in the literature on the specification of efficient and sufficient IMs in estimating seismic demands of structures. The most commonly used IMs for structural buildings are peak ground acceleration (PGA), peak ground velocity (PGV), and spectral acceleration at the fundamental period of structure $\left(S_{A}\left(T_{1}\right)\right)$. Elenas and Meskouris [45] studied the correlation between alternative IM parameters and damage indices of reinforced concrete frames. They concluded that PGV correlates well to the displacement response EDPs compared to PGA. Akkar and Küçükdoğan [46] also confirmed that PGV can be considered as a reasonable IM for 
TABLE 4: The ground motion records used in this study.

\begin{tabular}{|c|c|c|c|c|c|}
\hline No. & Earthquake name & Station name & Year & $M$ & $R(\mathrm{~km})$ \\
\hline 1 & San Fernando & LA-Hollywood Stor FF & 1971 & 6.61 & 22.8 \\
\hline 2 & Loma Prieta & Gilroy Array \#3 & 1989 & 6.93 & 12.8 \\
\hline 3 & Landers & Yermo Fire Station & 1992 & 7.28 & 23.6 \\
\hline 4 & Duzce, Turkey & Bolu & 1999 & 7.14 & 12.0 \\
\hline 5 & Northridge-01 & Canyon Country-W Lost Cany & 1994 & 6.69 & 12.4 \\
\hline 6 & Borah Peak & TRA-642 ETR Reactor Bldg & 1983 & 6.88 & 79.6 \\
\hline 7 & San Fernando & Santa Felita Dam & 1971 & 6.61 & 24.9 \\
\hline 8 & Irpinia, Italy-02 & Sturno & 1980 & 6.20 & 20.4 \\
\hline 9 & Loma Prieta & APEEL 10-Skyline & 1989 & 6.93 & 41.9 \\
\hline 10 & Loma Prieta & WAHO & 1989 & 6.93 & 17.5 \\
\hline 11 & Georgia, USSR & Ambralauri & 1991 & 6.20 & 63.6 \\
\hline 12 & Loma Prieta & Gilroy Array \#7 & 1989 & 6.93 & 22.7 \\
\hline 13 & Taiwan SMART1 (45) & SMART1 O10 & 1986 & 7.30 & 56.9 \\
\hline 14 & Irpinia, Italy-02 & Bovino & 1980 & 6.20 & 43.5 \\
\hline 15 & Coalinga-01 & Parkfield-Cholame 12W & 1983 & 6.36 & 55.8 \\
\hline 16 & N. Palm Springs & Winchester Page Bros R & 1986 & 6.06 & 38.2 \\
\hline 17 & San Fernando & 2516 Via Tejon PV & 1971 & 6.61 & 55.2 \\
\hline 18 & Superstition Hills-02 & Plaster City & 1987 & 6.54 & 22.3 \\
\hline 19 & Superstition Hills-02 & Superstition Mtn Camera & 1987 & 6.54 & 15.6 \\
\hline 20 & Superstition Hills-02 & Calipatria Fire Station & 1987 & 6.54 & 27.0 \\
\hline
\end{tabular}

predicting the peak nonlinear displacement response of structural systems. On the other hand, a number of previous studies have shown that $S_{A}\left(T_{1}\right)$ is a more efficient IM than PGA for drift response EDPs [47, 48]. However, for some structures, $S_{A}\left(T_{1}\right)$ may produce undesirable results from the efficiency or the sufficiency point of view [44, 49-54]. Cordova et al. [49] proposed a two-parameter seismic intensity measure, $S_{A}\left(T_{1}\right) R_{S a}^{0.5}$, which reflects both spectral intensity and shape. Their results indicated that the proposed IM significantly decreases the number of ground motion records necessary in time history analyses. Vamvatsikos and Cornell [50] studied three different types of building with different fundamental periods and found that when the influence of higher modes is negligible, taking the spectral acceleration at an optimum period higher than the firstmode period provides good efficiency. Bianchini et al. [55] and Pirizadeh and Shakib [56] demonstrated that $S_{A \text {,avg }}$ equal to $S_{A}\left(\alpha T_{1}-\eta T_{1}\right)$ which is defined as the elastic 5\%damped geometric mean of the spectral accelerations over the range of periods from $\alpha T_{1}$ to $\eta T_{1}$ with $\alpha=0.5$ and $\eta=1.5$ is an appropriate IM for multistory steel moment-resisting frame buildings. It was concluded that selecting $S_{A, \text { avg }}$ as the IM can significantly reduce the variability of IDA curves with respect to the elastic 5\%-damped first-mode spectral acceleration $\left(S_{A}\left(T_{1}, 5 \%\right)\right)$ and PGA. Eads et al. [57] studied the performance of spectral acceleration averaged over a period range $\left(S_{A, \text { avg }}\right)$ as an IM for estimating the collapse risk of the RC multistory moment-resisting frame and also walltype structures. They concluded that $S_{A \text { avg }}$, calculated using an appropriate period range, is generally more efficient and sufficient and provides more stable collapse risk estimates than $S_{A}\left(T_{1}\right)$. They also found that a period range from $0.2 T_{1}$ to $3 T_{1}$ is more likely to be an optimal range for considered structures. Tsantaki et al. [52] compared two alternative IMs, $S_{A \text { avg }}$ and $S_{A}\left(T_{1}\right)$ considering P-delta effects, with the widely used IM, and $S_{A}\left(T_{1}\right)$ without P-delta, and found that both proposed IMs are more efficient than the benchmark IM. In this study, $S_{A}\left(T_{1}-1.6 T_{1}\right)$ was suggested as an optimal averaged IM for SDOF structures with fundamental periods larger than $0.15 \mathrm{sec}$. Kohrangi et al. $[53,54]$ investigated the efficiency and sufficiency of scalar and vector ground motion IMs including $S_{A}\left(T_{1}\right)$ and $S_{A \text {,avg }}$ for the seismic response assessment of RC frame buildings. They observed that $S_{A \text {,avg }}$ is more likely to be the most efficient IM in the estimation of structural responses. However, employing vector IMs leads to an improvement in response prediction efficiency. AlBaadani and Al-Shameri [58] investigated several IMs for evaluation of the seismic response of RC frame minarets and concluded that the optimal IM for these structures is $S_{A}\left(T_{1}, 2 T_{1}\right)$ which defines as the geometric mean of the spectral accelerations at $T_{1}$ and $2 T_{1}$. Colajanni et al. [59] carried out a correlation study between interstory drift ratios and three different intensity measure parameters, including PGA, PGV, and $S_{A}\left(T_{1}\right)$ in irregular RC structures. The results of their study confirmed that PGV is highly correlated to drift responses, and as a result, it is more efficient than PGA and $S_{A}\left(T_{1}\right)$.

Based on the IMs used in the abovementioned studies, 30 different IMs as categorized in Table 5 were considered as potential IMs for predicting the seismic response of the considered structural models in this study. The optimal one was identified based on both efficiency and sufficiency characteristics.

4.1.1. Efficiency. According to Reference [60], a natural logarithmic correlation can be chosen between EDP and IM to utilize a linear regression of the natural logarithms of IM and EDP:

$$
\mathrm{EDP}=a(\mathrm{IM})^{b} \longrightarrow \ln (\mathrm{EDP})=\ln (a)+b \ln (\mathrm{IM}) .
$$

Thus, efficiency can be measured based on the conditional standard deviation of the regression, $\sigma_{\ln \text { EDP|IM }}$, which 
TABLE 5: Intensity measures considered in the analysis.

\begin{tabular}{lcc}
\hline IM no. & Intensity measure descriptor & Definition \\
\hline 1 & PGA & Peak ground acceleration \\
2 & PGV & Peak ground velocity \\
3 & PGD & Peak ground displacement \\
4 & $S_{A}\left(T_{1}\right)$ & Spectral acceleration at fundamental period \\
5 & $S_{A}\left(T_{1}, T_{2}, T_{3}\right)$ & Geometric mean of the spectral accelerations at $T_{1}, T_{2}$, and $T_{3}$ \\
6 & $S_{A}\left(T_{1}, 2 T_{1}\right)$ & Geometric mean of the spectral accelerations at $T_{1}$ and $2 T_{1}$ \\
& & Geometric mean of the spectral accelerations over the range of periods from $\alpha T_{1}$ to $\eta T_{1}$ \\
$7-30$ & $S_{A}\left(\alpha T_{1}-\eta T_{1}\right)$ & $\alpha=0.2,0.5,0.75$ and 1 \\
& & $\eta=1.5,2,2.5,3,3.5$ and 4 \\
\hline
\end{tabular}

depends on two regression coefficients $(a, b)$ and can be calculated by equation (11). The lower values of $\sigma$ belong to a more efficient IM $[58,61,62]$ :

$$
\sigma_{\ln \mathrm{EDP} \mid \mathrm{IM}}=\beta_{\mathrm{EDP} \mid \mathrm{IM}}=\sqrt{\frac{\sum(\ln (\mathrm{EDP})-\ln (a)-b \ln (\mathrm{IM}))^{2}}{m-2}},
$$

where the total number of dynamic analyses has been denoted by $m$.

The results of regression analysis for all investigated IMs, in terms of dispersion values $(\sigma)$, are presented in Table 6 for the symmetric model of reference and six asymmetric models with different $\beta$ values as defined in Table 1 . It can be seen that in all models, the maximum value for $\sigma$ among all IMs belongs to PGD (IM no. 3), which shows that this IM is the least effective one. After PGD, PGA (no. 1), $S_{A}\left(0.2 T_{1}-\right.$ $1.5 T_{1}$ ) (no. 7), and $S_{A}\left(T_{1}-4 T_{1}\right)$ (no. 30) have less efficiency in most cases. Furthermore, it can be observed that among peak ground responses, PGV (IM no. 2) with lower dispersion values represents a good IM from the efficiency point of view compared to PGA and PGD. The efficiency of this velocity-based IM is even higher than that of some spectral acceleration-based IMs, including $S_{A}\left(T_{1}\right)$, $S_{A}\left(T_{1}, 2 T_{1}\right), \quad S_{A}\left(0.75 T_{1}-4 T_{1}\right), \quad S_{A}\left(T_{1}-3.5 T_{1}\right), \quad$ and $S_{A}\left(T_{1}-4 T_{1}\right)$. Among all IMs, $S_{A}\left(0.5 T_{1}-2.5 T_{1}\right)$ (no. 15) has the smallest dispersion value for the asymmetric models with $\beta=-1.0$ and -0.5 , which have large stiffness eccentricities. In the other models, $S_{A}\left(0.75 T_{1}-2.5 T_{1}\right)$ (no. 21) with minimum $\sigma$ is the most efficient IM.

Figure 5 demonstrates a comparison between the least and the most efficient IMs for the symmetric model (PGD and $\left.S_{A}\left(0.75 T_{1}-2.5 T_{1}\right)\right)$. It is observed that there is a higher dispersion in the diagram $\ln \left(\theta_{\max }\right)$ and $\ln (\mathrm{PGD})$ than that in $\ln \left(\theta_{\max }\right)$ and $\ln \left(S_{A}\left(0.75 T_{1}-2.5 T_{1}\right)\right)$. The corresponding results are shown in Figure 6 for the asymmetric model with $\beta=-1.0$, where it is seen that the scattering about the regression trend line for $S_{A}\left(0.5 T_{1}-2.5 T_{1}\right)$, as the most efficient IM, is smaller than that for PGD.

4.1.2. Sufficiency. Using a one-parameter regression analysis of the residuals on the earthquake record characteristics ( $M$ and $\ln (R)$ ) simplifies the procedure for quantifying the sufficiency of an IM [44]. The residuals indicate the difference between the EDP values obtained from dynamic analysis and the estimated ones from the regression fit.
According to Reference [44], the statistical significance of the regression estimate on $M$ and $\ln (R)$ and consequently the sufficiency of IM can be measured by the $p$ value, so that a small $p$ value for a given IM (less than about 0.05 ) indicates that the considered IM is insufficient.

The sufficiency results of all considered IMs are presented in Table 7, where the $p$ values higher than 0.05 for both $M$ and $R$ parameters are highlighted. As shown in the table, the sufficiency of $S_{A}\left(0.5 T_{1}-2.5 T_{1}\right)$ (IM no. 15) and $S_{A}\left(0.75 T_{1}-2.5 T_{1}\right)$ (no. 21$)$, which were the most efficient IMs, is not acceptable. Among peak ground responses, only PGV in the symmetric model provides good sufficiency with respect to both $M$ and $R$ parameters. It can also be seen that $S_{A}\left(0.5 T_{1}-4 T_{1}\right)$ (no. 18), $S_{A}\left(0.75 T_{1}-3.5 T_{1}\right)$ (no. 23), $S_{A}\left(0.75 T_{1}-4 T_{1}\right)$ (no. 24), $S_{A}\left(T_{1}-3.5 T_{1}\right)$ (no. 29), and $S_{A}\left(T_{1}-4 T_{1}\right)$ (no. 30) are sufficient IMs in terms of $M$ and $R$ for all models. On the other hand, according to Table 6, $S_{A}\left(0.75 T_{1}-3.5 T_{1}\right)$ has the least $\sigma$ among these five sufficient IMs and hence is the most efficient of the group. Therefore, $S_{A}\left(0.75 T_{1}-3.5 T_{1}\right)$ is selected as the optimal IM for the structural models used in this study. For example, the sufficiency results of this IM are presented in Figures 7 and 8 for the symmetric model and the asymmetric model with $\beta=-1.0$, respectively. For improved readability, $S_{A}\left(0.75 T_{1}-3.5 T_{1}\right)$ is renamed $S_{A \text {,avg }}$ in the IDA curves presented in the next sections.

4.2. Interstory Drift Capacities. In this paper, following the ASCE 41-13 [27], three common performance levels, including immediate occupancy (IO), life safety (LS), and collapse prevention (CP) levels are used for the probabilistic performance-based analysis. According to this code, the interstory drift capacities for these performance levels are determined to be $0.5 \%, 1 \%$, and $2 \%$ for RC wall-type buildings, and $1 \%, 2 \%$, and $4 \%$ for RC frame buildings, respectively. However, there is no information about the interstory drift capacities for wall-frame buildings. Jeong et al. [63] used the limit states of ductile walls suggested in Reference [64] for fragility analysis of wall-frame buildings in their study; these interstory drift capacities were $0.7 \%$, $1.5 \%$, and $2.5 \%$ for the IO, LS, and CP performance levels, respectively. In this section, an attempt has been made to obtain a more precise estimate of the interstory drift capacities for the wall-frame buildings used in this study. For this purpose, a damage index concept was used based on the idea that the state of structural damage due to seismic loads 
TABLE 6: The dispersion values $(\sigma)$ obtained from regression analysis for all IMs.

\begin{tabular}{|c|c|c|c|c|c|c|c|c|}
\hline \multirow{2}{*}{ IM no. } & \multirow{2}{*}{ IM } & \multicolumn{7}{|c|}{$\sigma$} \\
\hline & & Sym. model & $\beta=-1.0$ & $\beta=-0.5$ & $\beta=0.0$ & $\beta=0.5$ & $\beta=0.75$ & $\beta=1.0$ \\
\hline 1 & PGA & 0.509 & 0.461 & 0.471 & 0.514 & 0.492 & 0.509 & 0.523 \\
\hline 2 & PGV & 0.381 & 0.370 & 0.344 & 0.389 & 0.347 & 0.367 & 0.371 \\
\hline 3 & PGD & 0.854 & 0.798 & 0.782 & 0.812 & 0.800 & 0.829 & 0.854 \\
\hline 4 & $S_{A}\left(T_{1}\right)$ & 0.423 & 0.371 & 0.379 & 0.434 & 0.403 & 0.414 & 0.411 \\
\hline 5 & $S_{A}\left(T_{1}, T_{2}, T_{3}\right)$ & 0.422 & 0.369 & 0.379 & 0.433 & 0.399 & 0.411 & 0.411 \\
\hline 6 & $S_{A}\left(T_{1}, 2 T_{1}\right)$ & 0.423 & 0.371 & 0.379 & 0.434 & 0.403 & 0.414 & 0.411 \\
\hline 7 & $S_{A}\left(0.2 T_{1}-1.5 T_{1}\right)$ & 0.439 & 0.387 & 0.402 & 0.454 & 0.419 & 0.428 & 0.434 \\
\hline 8 & $S_{A}\left(0.2 T_{1}-2 T_{1}\right)$ & 0.377 & 0.334 & 0.345 & 0.401 & 0.354 & 0.357 & 0.361 \\
\hline 9 & $S_{A}\left(0.2 T_{1}-2.5 T_{1}\right)$ & 0.340 & 0.311 & 0.313 & 0.375 & 0.319 & 0.318 & 0.321 \\
\hline 10 & $S_{A}\left(0.2 T_{1}-3 T_{1}\right)$ & 0.335 & 0.315 & 0.312 & 0.370 & 0.315 & 0.314 & 0.316 \\
\hline 11 & $S_{A}\left(0.2 T_{1}-3.5 T_{1}\right)$ & 0.345 & 0.330 & 0.320 & 0.372 & 0.325 & 0.326 & 0.326 \\
\hline 12 & $S_{A}\left(0.2 T_{1}-4 T_{1}\right)$ & 0.361 & 0.348 & 0.334 & 0.381 & 0.342 & 0.345 & 0.344 \\
\hline 13 & $S_{A}\left(0.5 T_{1}-1.5 T_{1}\right)$ & 0.398 & 0.347 & 0.362 & 0.417 & 0.376 & 0.379 & 0.380 \\
\hline 14 & $S_{A}\left(0.5 T_{1}-2 T_{1}\right)$ & 0.346 & 0.306 & 0.314 & 0.373 & 0.319 & 0.316 & 0.315 \\
\hline 15 & $S_{A}\left(0.5 T_{1}-2.5 T_{1}\right)$ & 0.323 & 0.298 & 0.297 & 0.358 & 0.299 & 0.294 & 0.292 \\
\hline 16 & $S_{A}\left(0.5 T_{1}-3 T_{1}\right)$ & 0.332 & 0.315 & 0.309 & 0.365 & 0.309 & 0.307 & 0.305 \\
\hline 17 & $S_{A}\left(0.5 T_{1}-3.5 T_{1}\right)$ & 0.355 & 0.342 & 0.329 & 0.378 & 0.333 & 0.334 & 0.332 \\
\hline 18 & $S_{A}\left(0.5 T_{1}-4 T_{1}\right)$ & 0.378 & 0.367 & 0.350 & 0.393 & 0.358 & 0.362 & 0.360 \\
\hline 19 & $S_{A}\left(0.75 T_{1}-1.5 T_{1}\right)$ & 0.388 & 0.34 & 0.353 & 0.406 & 0.364 & 0.364 & 0.361 \\
\hline 20 & $S_{A}\left(0.75 T_{1}-2 T_{1}\right)$ & 0.336 & 0.299 & 0.305 & 0.362 & 0.307 & 0.301 & 0.296 \\
\hline 21 & $S_{A}\left(0.75 T_{1}-2.5 T_{1}\right)$ & 0.322 & 0.302 & 0.299 & 0.357 & 0.298 & 0.292 & 0.288 \\
\hline 22 & $S_{A}\left(0.75 T_{1}-3 T_{1}\right)$ & 0.344 & 0.330 & 0.321 & 0.373 & 0.320 & 0.318 & 0.316 \\
\hline 23 & $S_{A}\left(0.75 T_{1}-3.5 T_{1}\right)$ & 0.375 & 0.363 & 0.349 & 0.393 & 0.352 & 0.355 & 0.353 \\
\hline 24 & $S_{A}\left(0.75 T_{1}-4 T_{1}\right)$ & 0.403 & 0.391 & 0.373 & 0.411 & 0.381 & 0.386 & 0.385 \\
\hline 25 & $S_{A}\left(T_{1}-1.5 T_{1}\right)$ & 0.394 & 0.347 & 0.359 & 0.408 & 0.369 & 0.366 & 0.362 \\
\hline 26 & $S_{A}\left(T_{1}-2 T_{1}\right)$ & 0.342 & 0.306 & 0.311 & 0.364 & 0.312 & 0.303 & 0.297 \\
\hline 27 & $S_{A}\left(T_{1}-2.5 T_{1}\right)$ & 0.335 & 0.316 & 0.311 & 0.366 & 0.310 & 0.303 & 0.299 \\
\hline 28 & $S_{A}\left(T_{1}-3 T_{1}\right)$ & 0.362 & 0.348 & 0.338 & 0.387 & 0.338 & 0.336 & 0.334 \\
\hline 29 & $S_{A}\left(T_{1}-3.5 T_{1}\right)$ & 0.397 & 0.384 & 0.369 & 0.410 & 0.373 & 0.376 & 0.375 \\
\hline 30 & $S_{A}\left(T_{1}-4 T_{1}\right)$ & 0.425 & 0.412 & 0.394 & 0.429 & 0.403 & 0.409 & 0.408 \\
\hline
\end{tabular}

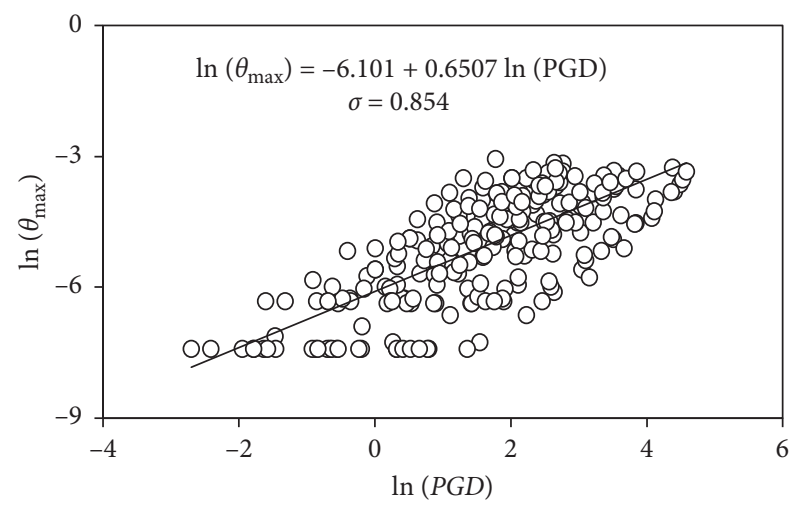

(a)

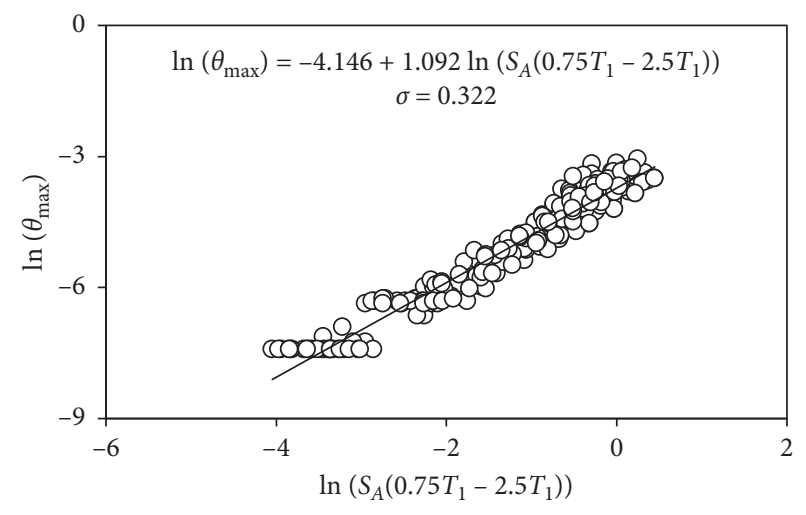

(b)

FIGURE 5: Comparison of the efficiency of two IMs for the symmetric model: (a) PGD; (b) $S_{A}\left(0.75 T_{1}-2.5 T_{1}\right)$.

can be quantified by a mathematical indicator called the damage index (DI). The most commonly used damage index is the Park-Ang model [65] that is expressed by deformation and hysteretic energy due to an earthquake excitation. Kunnath et al. [66] recommended a modification for the Park-Ang model in which the deformation terms of the model were replaced by the rotation ones as presented in the following equation:

$$
\mathrm{DI}_{\text {component }}=\frac{\theta_{m}-\theta_{r}}{\theta_{u}-\theta_{r}}+\beta \frac{E_{h}}{M_{y} \theta_{u}},
$$




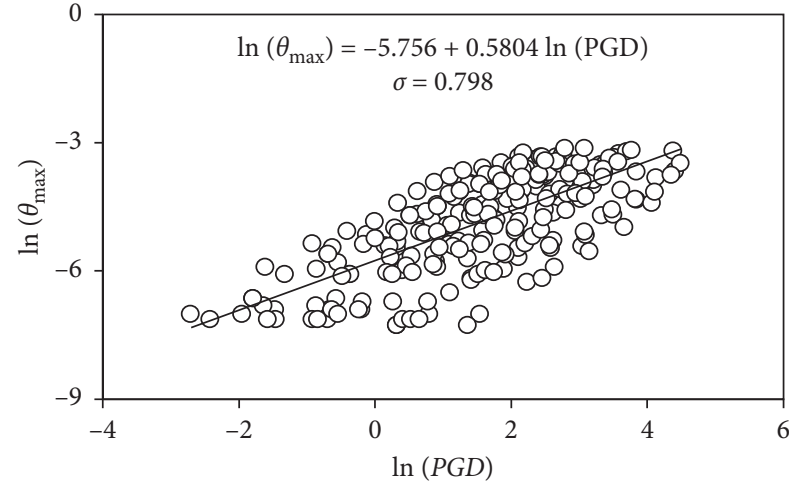

(a)

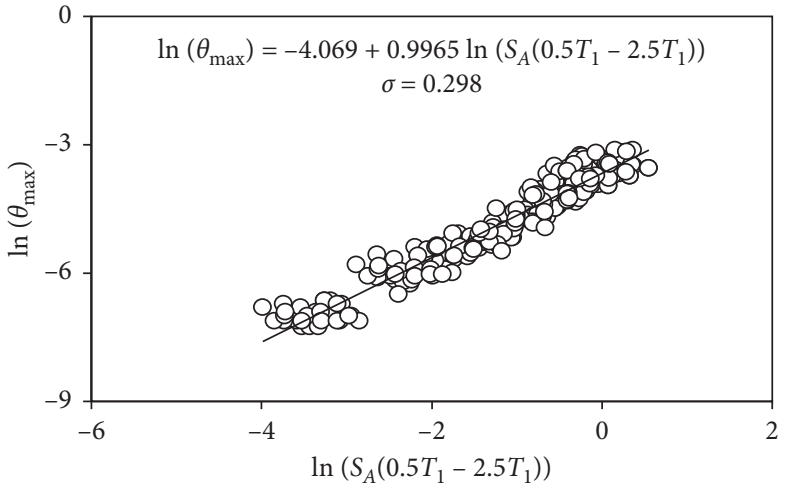

(b)

Figure 6: Comparison of the efficiency of two IMs for the asymmetric model with $\beta=-1.0$ : (a) PGD; (b) $S_{A}\left(0.5 T_{1}-2.5 T_{1}\right)$.

TABLE 7: The $p$ values obtained from regression analysis for all IMs.

\begin{tabular}{|c|c|c|c|c|c|c|c|c|c|c|c|c|c|c|c|}
\hline \multirow{3}{*}{ IM no. } & \multirow{3}{*}{ IM } & \multicolumn{14}{|c|}{$p$ values } \\
\hline & & \multicolumn{2}{|c|}{ Sym. model } & \multicolumn{2}{|c|}{$\beta=-1.0$} & \multicolumn{2}{|c|}{$\beta=-0.5$} & \multicolumn{2}{|c|}{$\beta=0.0$} & \multicolumn{2}{|c|}{$\beta=0.5$} & \multicolumn{2}{|c|}{$\beta=0.75$} & \multicolumn{2}{|c|}{$\beta=1.0$} \\
\hline & & $M$ & $R$ & $M$ & $R$ & $M$ & $R$ & $M$ & $R$ & $M$ & $R$ & $M$ & $R$ & $M$ & $R$ \\
\hline 1 & $\mathrm{P}$ & 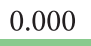 & & & & & & & & & & 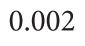 & & 00 & 083 \\
\hline 2 & PGV & 32 & 31 & & & & & & & & & & & & \\
\hline 3 & PGD & 00 & 518 & & & & & & & & & & & & 370 \\
\hline 4 & $S_{A}\left(T_{1}\right)$ & 00 & 305 & 000 & & 000 & 0.266 & .000 & 0.154 & .000 & & .001 & & .000 & 841 \\
\hline 5 & $\left(T_{1}, T_{2}, T_{3}\right)$ & 000 & 0.105 & .000 & 0.231 & 0.000 & 0.085 & .000 & 0.049 & 0.000 & 0.154 & 0.000 & 0.501 & .000 & .686 \\
\hline 6 & $S_{A}\left(T_{1}, 2 T_{1}\right)$ & 000 & 0.305 & 000 & 588 & .000 & 0.266 & .000 & 0.154 & 0.000 & .432 & .001 & 35 & .000 & .841 \\
\hline 7 & $S_{A}\left(0.2 T_{1}-1.5 T_{1}\right)$ & 0.000 & 0.088 & 0.000 & 2 & 0.000 & 0.078 & .000 & 0.045 & 0.001 & 7 & 002 & 96 & .000 & 0.627 \\
\hline 8 & $S_{A}\left(0.2 T_{1}-2 T_{1}\right)$ & 0.000 & 0.053 & .002 & 0.179 & 0.000 & 0.045 & .002 & 0.026 & 0.002 & 0.102 & 0.004 & 0.473 & .000 & 0.644 \\
\hline 9 & $S_{A}\left(0.2 T_{1}-2.5 T_{1}\right)$ & 0.000 & 0.044 & .003 & 0.179 & 0.007 & 0.030 & .027 & 0.018 & 0.028 & 0.087 & .048 & 0.466 & .003 & .744 \\
\hline 10 & $S_{A}\left(0.2 T_{1}-3 T_{1}\right)$ & 0.009 & 0.048 & 015 & 209 & .025 & 0.029 & .141 & 0.017 & 0.030 & 0.090 & .030 & & .032 & 0.839 \\
\hline 11 & $S_{A}\left(0.2 T_{1}-3.5 T_{1}\right)$ & 0.152 & 0.070 & 022 & 0.280 & 0.033 & 0.040 & 579 & 0.054 & 0.751 & 0.118 & 025 & & .029 & 0.971 \\
\hline 12 & $S_{A}\left(0.2 T_{1}-4 T_{1}\right)$ & 0.510 & 0.222 & & & & & 73 & & 0.743 & & & & .014 & 0.617 \\
\hline 13 & $\left.T_{1}-1.5 T_{1}\right)$ & 0.000 & 0.004 & 0.001 & & 0 & 0.0 & 0.000 & & 0.001 & & 002 & & .000 & 0.098 \\
\hline 14 & $S_{A}\left(0.5 T_{1}-2 T_{1}\right)$ & 00 & 0.004 & .013 & 0 & 1 & 0. & 06 & & 0.006 & & .003 & & .000 & 0.154 \\
\hline 15 & $S_{A}\left(0.5 T_{1}-2.5 T_{1}\right)$ & 0.006 & 0.006 & 0.001 & 0.0 & 0.0 & 0.0 & 0.108 & 0.0 & 0.121 & & 0.005 & & .002 & 0.297 \\
\hline 16 & $5 T_{1}-$ & 0.081 & 0.015 & 0.024 & 0.091 & & & 0.412 & & & & .023 & & & 0.473 \\
\hline 17 & $\left.T_{1}-3.5 T_{1}\right)$ & 0.546 & 0.037 & 0.035 & 0.177 & 0.023 & 0.019 & 0.934 & 0.0 & 0.706 & 0. & 0.026 & & 0.022 & 0.691 \\
\hline 18 & $\left.5 T_{1}-4 T_{1}\right)$ & 0.953 & 0.169 & 0.170 & 0.466 & 0.638 & 0.096 & 0.549 & & 0.359 & & 0.276 & & 0.359 & 0.813 \\
\hline 19 & $5 T_{1}-1$ & 0.000 & 0.000 & 0.143 & 0.012 & 0.012 & 0.000 & 0.041 & 0.001 & 0.063 & 0.003 & 0.083 & 0.000 & 0.002 & 0.093 \\
\hline 20 & $\left.75 T_{1}-2 T_{1}\right)$ & & & & & & & & & & & & & & 0.115 \\
\hline 21 & $\left.5 T_{1}-2.5 T_{1}\right)$ & 0.100 & 0.008 & 0.995 & 0.003 & 0.331 & 0.004 & 0.453 & 0.003 & 0.572 & 0.017 & 0.779 & 0.004 & 0.008 & 0.314 \\
\hline 22 & $\left.5 T_{1}-3 T_{1}\right)$ & 0.432 & 0.022 & 0.471 & 0.122 & 0.841 & 0.120 & 0.947 & 0.007 & 0.842 & 0.041 & 0.665 & 0.223 & 0.995 & 0.536 \\
\hline 23 & $\left.5 T_{1}-3.5 T_{1}\right)$ & 0.864 & 0.058 & 0.135 & 0.233 & 0.538 & 0.890 & 0.474 & 0.260 & 0.295 & 0.091 & 0.219 & 0.334 & 0.299 & 0.770 \\
\hline 24 & $\left.4 T_{1}\right)$ & 0.498 & 0.233 & 0.062 & 0.559 & 0.310 & 0.137 & 0.261 & 0.065 & 0.149 & 0.311 & 0.106 & 0.710 & 0.120 & 0.743 \\
\hline 25 & $S_{A}\left(T_{1}-1.5 T_{1}\right)$ & 0.006 & 0.013 & 0.048 & 0.002 & 0.055 & 0.000 & 0.098 & 0.000 & 0.124 & 0.001 & 0.232 & 0.019 & 0.008 & 0.034 \\
\hline 26 & $S_{A}\left(T_{1}-2 T_{1}\right)$ & 0.024 & 0.001 & 0.489 & 0.009 & 0.113 & 0.001 & 0.186 & 0.001 & 0.264 & 0.002 & 0.361 & 0.027 & 0.066 & 0.047 \\
\hline 27 & $S_{A}\left(T_{1}-2.5 T_{1}\right)$ & 0.352 & 0.006 & 0.536 & 0.048 & 0.753 & 0.003 & 0.846 & 0.002 & 0.943 & 0.013 & 0.739 & 0.023 & 0.864 & 0.021 \\
\hline 28 & $S_{A}\left(T_{1}-3 T_{1}\right)$ & 0.827 & 0.023 & 0.237 & 0.126 & 0.761 & 0.055 & 0.698 & 0.006 & 0.489 & 0.042 & 0.370 & 0.207 & 0.523 & 0.497 \\
\hline 29 & $S_{A}\left(T_{1}-3.5 T_{1}\right)$ & 0.549 & 0.066 & 0.068 & 0.248 & 0.322 & 0.068 & 0.282 & 0.061 & 0.158 & 0.100 & 0.118 & 0.330 & 0.135 & 0.750 \\
\hline 30 & $S_{A}\left(T_{1}-4 T_{1}\right)$ & 0.314 & 0.257 & 0.051 & 0.587 & 0.193 & 0.155 & 0.158 & 0.073 & 0.086 & 0.334 & 0.062 & 0.711 & 0.058 & 0.756 \\
\hline
\end{tabular}

where $\theta_{m}$ is the maximum rotation during the loading time, $\theta_{u}$ is the ultimate rotation capacity, $\theta_{r}$ is the recoverable rotation when unloading, $M_{y}$ is the yield moment, and $E_{h}$ is the dissipated energy of each structural component.
DI for an individual story can be computed using the weighting factor based on hysteretic energy dissipated at the component $\left(E_{i}\right)$ as shown in the following equation: 


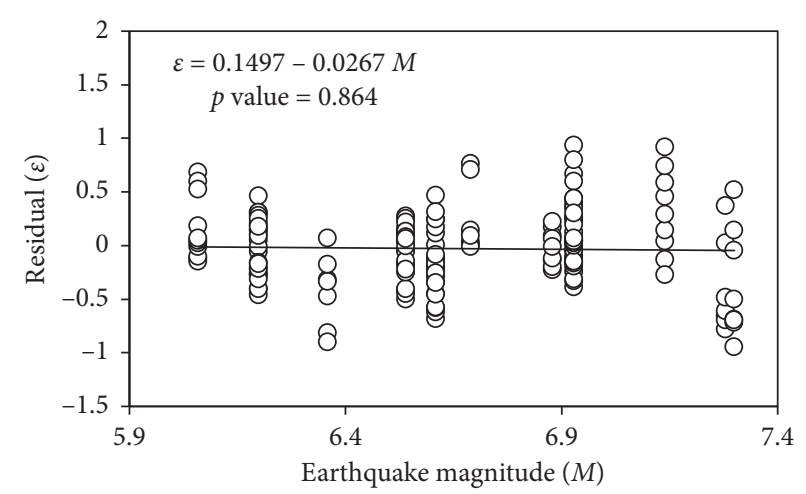

(a)

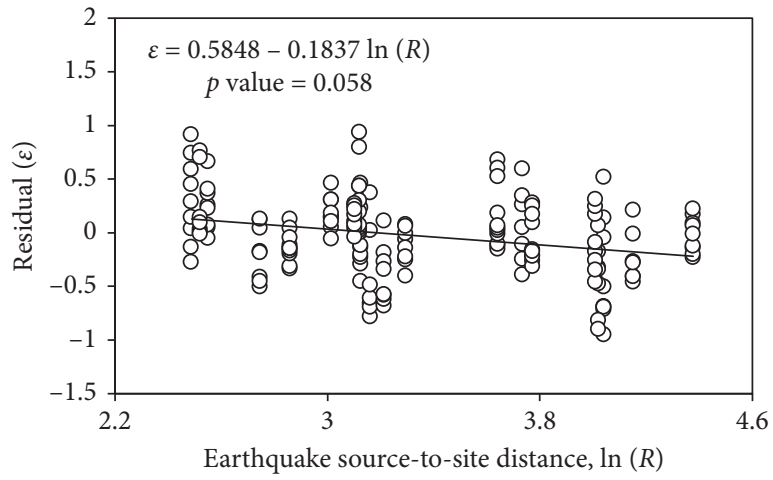

(b)

Figure 7: Sufficiency of $S_{A}\left(0.75 T_{1}-3.5 T_{1}\right)$ for the symmetric model with respect to (a) magnitude $(M)$ and (b) distance $(R)$.

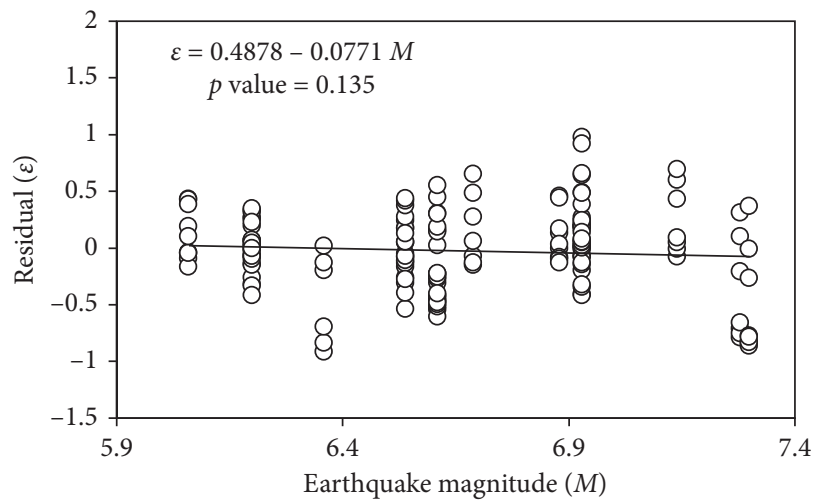

(a)

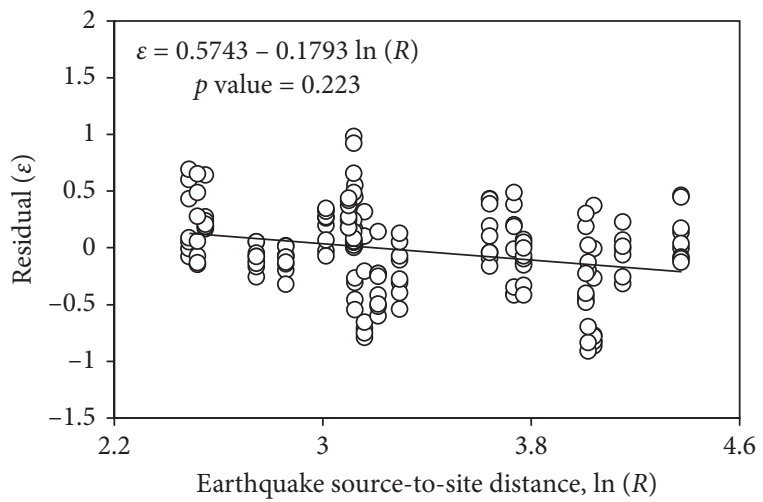

(b)

Figure 8: Sufficiency of $S_{A}\left(0.75 T_{1}-3.5 T_{1}\right)$ for the asymmetric model with $\beta=-1.0$ with respect to (a) magnitude $(M)$ and (b) distance $(R)$.

$$
\begin{aligned}
\mathrm{DI}_{\text {story }} & =\sum_{i=1}^{n} \lambda_{i, \text { component }} \cdot D I_{i, \text { component }}, \\
\lambda_{i, \text { component }} & =\left[\frac{E_{i}}{\sum_{i=1}^{n} E_{i}}\right]_{\text {component }} \cdot
\end{aligned}
$$

Park and Ang [65] classified damage levels into five categories defined in Table 8. According to this table, the interstory drift ratios in which the damage indices reach the limits of $0.25,0.4$, and 0.8 represent the interstory drift capacities for IO, LS, and CP performance levels, respectively. So, knowing this fact, in this paper, the following procedure was used to find the interstory drift capacities.

First, IDA curves were generated in the $S_{A \text {,avg }}-\theta_{\max }$ plane for each earthquake record. Then, based on nonlinear analysis data, the damage index in each intensity level $\left(S_{A \text {,avg }}\right)$ was calculated and the damage index curves versus $S_{A \text {,avg }}$ were obtained for all ground motion records, and the intensity levels $\left(S_{A, \text { avg }} s\right)$ corresponding to DI $=0.25,0.4$, and 0.8 were extracted from damage index curves. Finally, the interstory drift values corresponding to these $S_{A \text {,avg }} s$ were determined from IDA curves. For example, this procedure is shown for the symmetric model in Figure 9 and Table 9.
TABLE 8: The relation between damage index and damage state.

\begin{tabular}{lc}
\hline Damage state & Definition \\
\hline No damage & $\mathrm{DI}<0.1$ \\
Minor damage (IO performance level) & $0.1<\mathrm{DI}<0.25$ \\
Moderate damage (LS performance level) & $0.25<\mathrm{DI}<0.4$ \\
Severe damage (CP performance level) & $0.4<\mathrm{DI}<0.8$ \\
Collapse & $\mathrm{DI}>0.8$ \\
\hline
\end{tabular}

The same procedure was used for each structural model, and the average of interstory drift capacities for 20 ground motion records in each performance level was calculated (Table 10). Then, to have one unique criterion for the performance evaluation of all models, the average of the interstory drift capacities of the 10 models, as calculated in the last row of Table 10, was used as the interstory drift capacities for three performance levels. As it can be seen from the table, the interstory drift ratios of $0.9 \%, 1.6 \%$, and $2.9 \%$ were estimated as the IO, LS, and CP limit-state capacities, respectively, for the wall-frame structural models used in this study. It is worth noting that these values are between the two corresponding aforementioned interstory drift values proposed by ASCE 41-13 [27] for shear walls and $\mathrm{RC}$ moment-resisting frames in each limit state. 


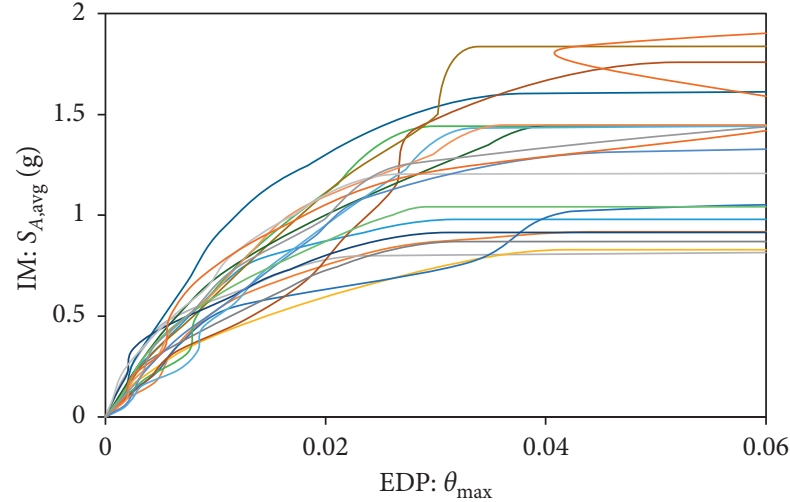

(a)

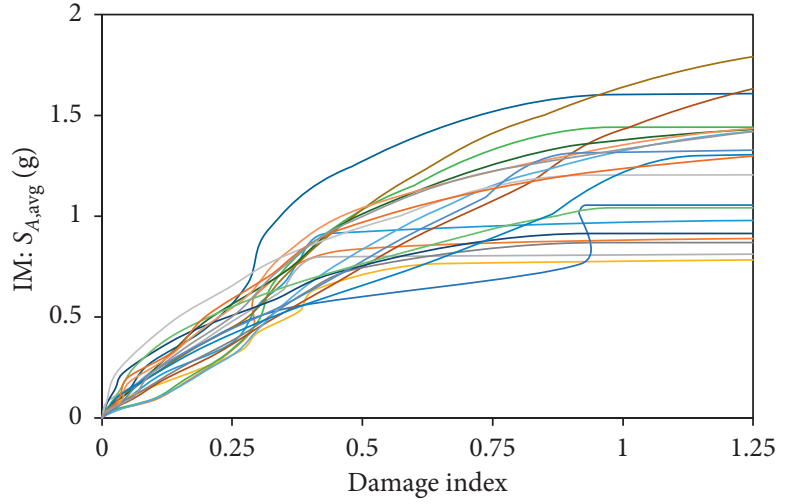

(b)

Figure 9: Damage analysis of the symmetric model: (a) interstory drift ratio versus $S_{A, \text { avg }}$; (b) damage index versus $S_{A, \text { avg }}$.

TABLE 9: $S_{A, \text { avg }}$ and interstory drift values corresponding to $\mathrm{DI}=0.25,0.4$, and 0.8 in the symmetric model.

\begin{tabular}{|c|c|c|c|c|c|c|}
\hline \multirow{2}{*}{ Record no. } & \multicolumn{2}{|c|}{$\mathrm{IO}(\mathrm{DI}=0.25)$} & \multicolumn{2}{|c|}{$\mathrm{LS}(\mathrm{DI}=0.4)$} & \multicolumn{2}{|c|}{$\mathrm{CP}(\mathrm{DI}=0.8)$} \\
\hline & $S_{A, \text { avg }}(\mathrm{g})$ & $\theta_{\max }(\%)$ & $S_{A, \text { avg }}(\mathrm{g})$ & $\theta_{\max }(\%)$ & $S_{A, \text { avg }}(\mathrm{g})$ & $\theta_{\max }(\%)$ \\
\hline 1 & 0.37 & 0.53 & 0.84 & 1.78 & 0.94 & 2.70 \\
\hline 2 & 0.35 & 0.66 & 0.75 & 2.06 & 0.86 & 2.96 \\
\hline 3 & 0.48 & 0.57 & 0.75 & 2.03 & 0.80 & 3.68 \\
\hline 4 & 0.32 & 0.67 & 0.60 & 2.06 & 0.77 & 3.25 \\
\hline 5 & 0.43 & 0.86 & 0.56 & 1.33 & 0.72 & 2.84 \\
\hline 6 & 0.35 & 0.76 & 0.85 & 1.39 & 1.30 & 2.57 \\
\hline 7 & 0.58 & 0.64 & 1.09 & 1.46 & 1.47 & 3.09 \\
\hline 8 & 0.37 & 0.82 & 0.60 & 1.60 & 1.14 & 2.62 \\
\hline 9 & 0.39 & 0.74 & 0.63 & 1.64 & 0.83 & 2.83 \\
\hline 10 & 0.46 & 0.71 & 0.82 & 1.41 & 1.44 & 2.86 \\
\hline 11 & 0.56 & 0.78 & 0.82 & 1.41 & 1.26 & 3.12 \\
\hline 12 & 0.31 & 0.81 & 0.67 & 1.34 & 1.18 & 2.60 \\
\hline 13 & 0.51 & 0.79 & 0.66 & 1.40 & 0.86 & 2.70 \\
\hline 14 & 0.55 & 0.85 & 0.89 & 1.47 & 1.24 & 2.69 \\
\hline 15 & 0.66 & 0.94 & 0.85 & 1.28 & 1.13 & 2.32 \\
\hline 16 & 0.44 & 0.78 & 0.63 & 1.26 & 1.18 & 3.24 \\
\hline 17 & 0.54 & 0.87 & 0.69 & 1.30 & 0.96 & 2.41 \\
\hline 18 & 0.41 & 0.89 & 0.57 & 1.35 & 0.95 & 2.49 \\
\hline 19 & 0.59 & 0.72 & 0.84 & 1.28 & 1.14 & 2.55 \\
\hline 20 & 0.51 & 0.76 & 0.84 & 1.52 & 1.24 & 2.72 \\
\hline$\theta_{\text {max,avg }}(\%)$ & \multicolumn{2}{|c|}{0.76} & \multicolumn{2}{|c|}{1.52} & \multicolumn{2}{|c|}{2.81} \\
\hline
\end{tabular}

TABLE 10: The average values of the interstory drift ratios corresponding to DI $=0.25,0.4$, and 0.8 in the models.

\begin{tabular}{|c|c|c|c|c|}
\hline \multirow{2}{*}{ Model no. } & \multirow{2}{*}{$\beta$} & \multicolumn{3}{|c|}{$\theta_{\text {max,avg }}(\%)$} \\
\hline & & $\mathrm{IO}(\mathrm{DI}=0.25)$ & $\mathrm{LS}(\mathrm{DI}=0.4)$ & $\mathrm{CP}(\mathrm{DI}=0.8)$ \\
\hline 1 & Sym. model & 0.76 & 1.52 & 2.81 \\
\hline 2 & -1.0 & 0.96 & 1.76 & 3.15 \\
\hline 3 & -0.75 & 0.94 & 1.72 & 3.05 \\
\hline 4 & -0.5 & 0.92 & 1.65 & 3.01 \\
\hline 5 & -0.25 & 0.90 & 1.61 & 2.95 \\
\hline 6 & 0.0 & 0.87 & 1.55 & 2.67 \\
\hline 7 & 0.25 & 0.82 & 1.49 & 2.80 \\
\hline 8 & 0.5 & 0.78 & 1.55 & 2.82 \\
\hline 9 & 0.75 & 0.82 & 1.60 & 2.90 \\
\hline 10 & 1.0 & 0.86 & 1.71 & 2.96 \\
\hline \multicolumn{2}{|c|}{ Average (\%) } & 0.9 & 1.6 & 2.9 \\
\hline
\end{tabular}


4.3. Median IDA Curves. For investigating the effects of strength distribution on the seismic response of the structures, the median IDA curves of all models (with different $\beta$ values) were derived, as shown in Figure 10. As expected, it is apparent from Figure 10 that the median IM capacities of all asymmetric models are reduced over the whole range of the response compared to the symmetric model. However, in most cases, the reduction effects of the flexible-base asymmetric models on the IM capacities are slightly higher than the fixedbase ones. In both fixed- and flexible-base conditions, the asymmetric models with $\beta=0.0,0.25$, and 0.5 have better performance than the other asymmetric models, which is also expected since these models have minimum strength eccentricity and balanced configurations. Furthermore, the largest IM capacity reduction happens in the asymmetric model with $\beta=-1.0$, which has maximum $e_{s}$ and $e_{r}$ compared to other asymmetric cases, and its stiffness and strength centers are both located on one side of the mass center.

The flexible effect of soil can be examined considering the curves shown in Figure 11. The three common performance levels, IO, LS, and CP, were also defined on the median IDA curves of this figure. Based on the results of the previous section, the IO and LS points are placed where $\theta_{\max }$ reaches $0.9 \%$ and $1.6 \%$, respectively, and the CP performance limit is violated at $\theta_{\max }=2.9 \%$. For a better comparison, the ratios of IM capacities of the models with flexible-base conditions to those of the corresponding model with fixed base are extracted from Figure 11 and shown in Figure 12. It is clear from this figure that the IM capacities corresponding to all performance levels of the flexible-base models reduce with regard to those of the fixed-base ones. The maximum reduction rate is about $11 \%$ which is observed in the asymmetric models with $\beta=-1.0$ and 1.0 for the IO performance level.

\section{Evaluation of Structural Performance}

The data from the IDA study are employed in the probabilistic seismic performance evaluation of structural models, which characterizes the reliability of the models under the seismic hazard levels [41, 67-69]. Based on this approach, the mean annual frequencies of exceeding structural performance levels and the confidence levels in satisfying performance objectives were used to quantify the effects of different strength distributions and also soil flexibility on the probabilistic performance of the structural models considered in this study. For this purpose, first a seismic hazard curve appropriate for this study is defined, and then the abovementioned quantities are evaluated in the next sections.

5.1. Seismic Hazard Curve. In this study, the seismic hazard curve defined in Figure 13 was used in the evaluation of the seismic performance of the models. This curve has been developed from the information of the base hazard curve of Tehran used in Reference [70]. The latter hazard curve, which has been obtained from the probabilistic seismic hazard analysis (PSHA) method, is for the elastic 5\%- damped first-mode spectral acceleration $\left(S_{A}\left(T_{1}, 5 \%\right)\right)$, while we needed a curve corresponding to the optimal IM used in this study $\left(S_{A \text {,avg }}=S_{A}\left(0.75 T_{1}-3.5 T_{1}\right)\right)$. In order to address this issue, a similar procedure to the one used in the previous paper of the author [56] was applied in the current study as well. Based on this procedure, the "standard design response spectrum" of the Iranian Seismic Design Code [22] for the considered site (Tehran) was used to infer $S_{A \text {,avg }}$ from $S_{A}\left(T_{1}\right)$. According to this code, the design spectral acceleration is defined as

$$
S_{A}(T)=A B I,
$$

in which $A$ is the site-specific earthquake acceleration which is equal to $0.35 \mathrm{~g}$ for Tehran, $I$ is the importance factor which is equal to 1.0 for residential buildings with "moderate importance," and $B$ is the building response factor which can be defined by the following formulas:

$$
B=B_{1} N ; \begin{cases}B_{1}=S_{0}+\left(S-S_{0}+1\right)\left(\frac{T}{T_{0}}\right), & 0<T<T_{0}, \\ B_{1}=S+1, & T_{0}<T<T_{s}, \\ B_{1}=(S+1)\left(\frac{T_{s}}{T}\right), & T>T_{s},\end{cases}
$$

where $T_{0}, T_{s}, S$, and $S_{0}$ are the parameters determined from the soil type and seismicity level.

As mentioned before, the structural models are assumed to be located in Tehran with very high seismicity and the underlying soil is classified as Type III. Therefore, according to the Iranian Seismic Design Code [22], the values of $T_{0}, T_{s}, S$, and $S_{0}$ are equal to $0.15,0.7,1.1$, and 1.75, respectively.

$N$ is the spectrum modification factor which is defined as

$$
\begin{cases}N=1, & T<T_{s}, \\ N=\frac{0.7}{4-T_{s}}\left(T-T_{s}\right)+1, & T_{s}<T<4 \mathrm{sec}, \\ N=1.7, & T>4 \mathrm{sec} .\end{cases}
$$

Based on the above formulas, the "standard design response spectrum" for the considered site is derived and shown in Figure 14.

By using the information of the design spectrum and considering the fact that all points on that have the same probability of occurrence, we can define a conversion factor of 0.835 between $S_{A \text {,avg }}$ and $S_{A}\left(T_{1}\right)$ and calculate the value of $S_{A \text {,avg }}$ corresponding to each $S_{A}\left(T_{1}\right)$ by equation (17). Final $S_{A \text {,avg }}$-based hazard curve used in the study is illustrated in Figure 13.

$$
S_{A, \mathrm{avg}}=\left(\frac{0.804}{0.963}\right) * S_{A}\left(T_{1}\right)=0.835 * S_{A}\left(T_{1}\right) .
$$




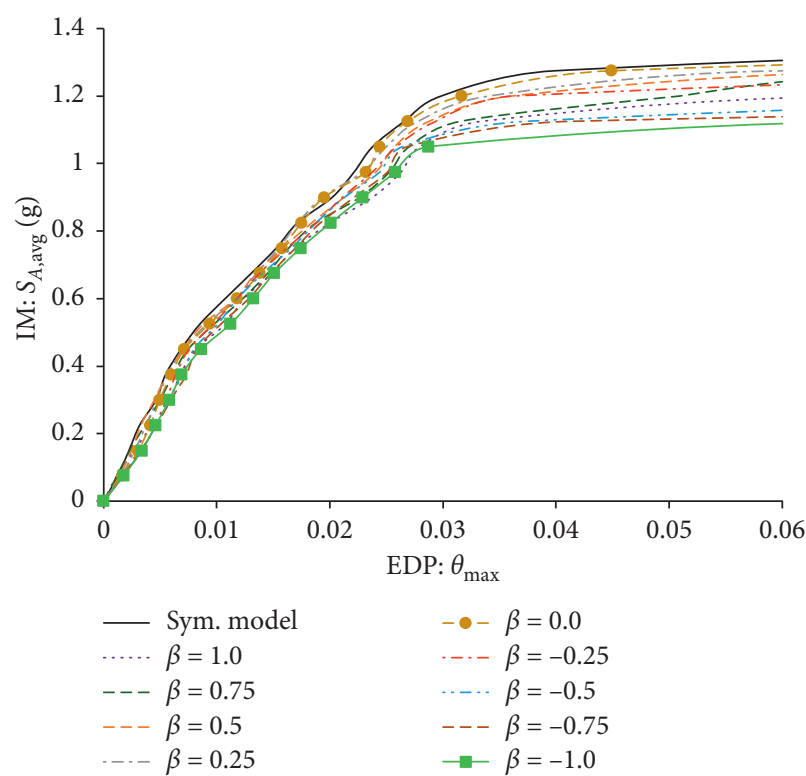

(a)

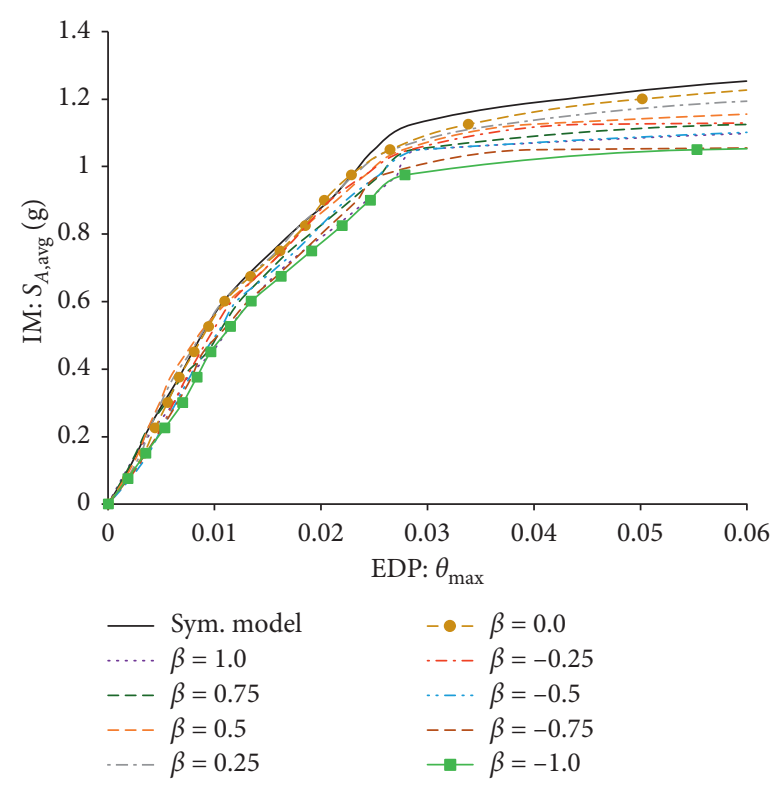

(b)

FIgURE 10: Median IDA curves of the symmetric and asymmetric models: (a) fixed base; (b) flexible base.

5.2. The Mean Annual Frequencies of Different Performance Limit States. In this section, the effect of strength distribution on the mean annual frequency (MAF) of exceeding the IO, LS, and CP performance levels in both fixed- and flexible-base models is evaluated. Here, the equations adopted by the Pacific Earthquake Engineering Research Center [60] are used to estimate the MAFs. In this framework, the general form of MAF is illustrated as

$$
\lambda_{P L}=\int F\left(\operatorname{IM}^{\hat{c}} \mid \mathrm{IM}\right)\left|\frac{\mathrm{d} \lambda(\mathrm{IM})}{\mathrm{dIM}}\right| \mathrm{dIM},
$$

where $F\left(\mathrm{IM}^{c} \mid \mathrm{IM}\right)$ is the cumulative distribution function (CDF) of the IM for a limit-state capacity and $\lambda$ (IM) is the spectral acceleration hazard.

By fitting a power-law function between the interstory drift demands and the spectral accelerations (as in equation (10)) and then considering a similar simplification for $\lambda$ (IM) at each level of IM $\left(\lambda(\mathrm{IM})=k_{0} \mathrm{IM}^{-k}\right)$, it is possible to provide a closed-form analytical solution for equation (18) and derive a straightforward equation for the MAF in the IM-based approach as follows [60]:

$$
\left.\lambda_{P L}=\lambda\left(\mathrm{IM}^{\widehat{c}}\right) e^{\left((1 / 2) k^{2} \beta^{2} \widehat{\mathrm{IM}^{c}}\right.}\right) .
$$

In this equation, $\mathrm{IM}^{c}$ is the median of the IM capacity, $k$ is the logarithmic slope of the locally approximated hazard curve at $\mathrm{IM}^{c}$, and $\beta_{\mathrm{IM}^{c}}$ is the standard deviation of the natural logarithm of the IM capacity. In this process, $\lambda\left(\mathrm{IM}^{c}\right)$ and $k$ are calculated by using the $S_{A \text {,avg-based hazard curve of Tehran }}$ illustrated in Figure 13.

It is also worth mentioning that equation (19) has so far been used by several researchers (e.g., Cordova et al. [49]; Jalayer and Cornell [69]; Pirizadeh and Shakib [56]; and Shakib and Homaei [37]) as a closed-form solution for calculating $\lambda_{P L}$. Additionally, the accuracy of the closedform solutions has also been examined by Medina [71] and Jalayer and Cornell [69], and it was observed that the results of the closed-form expression are reasonably close to those of the numerical integration.

In this section, the mean annual frequencies of exceeding the three common performance levels calculated by equation (19) for the symmetric and asymmetric models with fixed and flexible base are presented in Tables 11 and 12. Furthermore, Figure 15 shows the ratio of MAFs of asymmetric models to the symmetric one. According to the results, the following observations can be made:

(i) In most cases, the asymmetric models have larger MAF values in comparison with the symmetric model. Also, in the models with SSI effect, the difference between the MAF of the symmetric and asymmetric models is larger than in the fixed-base condition.

(ii) In the IO and LS performance levels, except for models with $\beta=0.5$ and 0.25 , the MAF values for the flexible-base asymmetric models increase by up to $60 \%$ relative to the symmetric model. The increase rate is about $40 \%$ in the models with fixed base.

(iii) The increase of MAF is more remarkable for the $\mathrm{CP}$ performance level. At this performance level, the MAF values for the asymmetric model with $\beta=-1.0$ (having maximum stiffness eccentricity) are approximately twice the MAF values for the symmetric model. After this case, the model with $\beta=-0.75$ has the maximum MAF value among the asymmetric models.

(iv) The minimum MAF values among the asymmetric models are highlighted in Tables 11 and 12 . It can be 

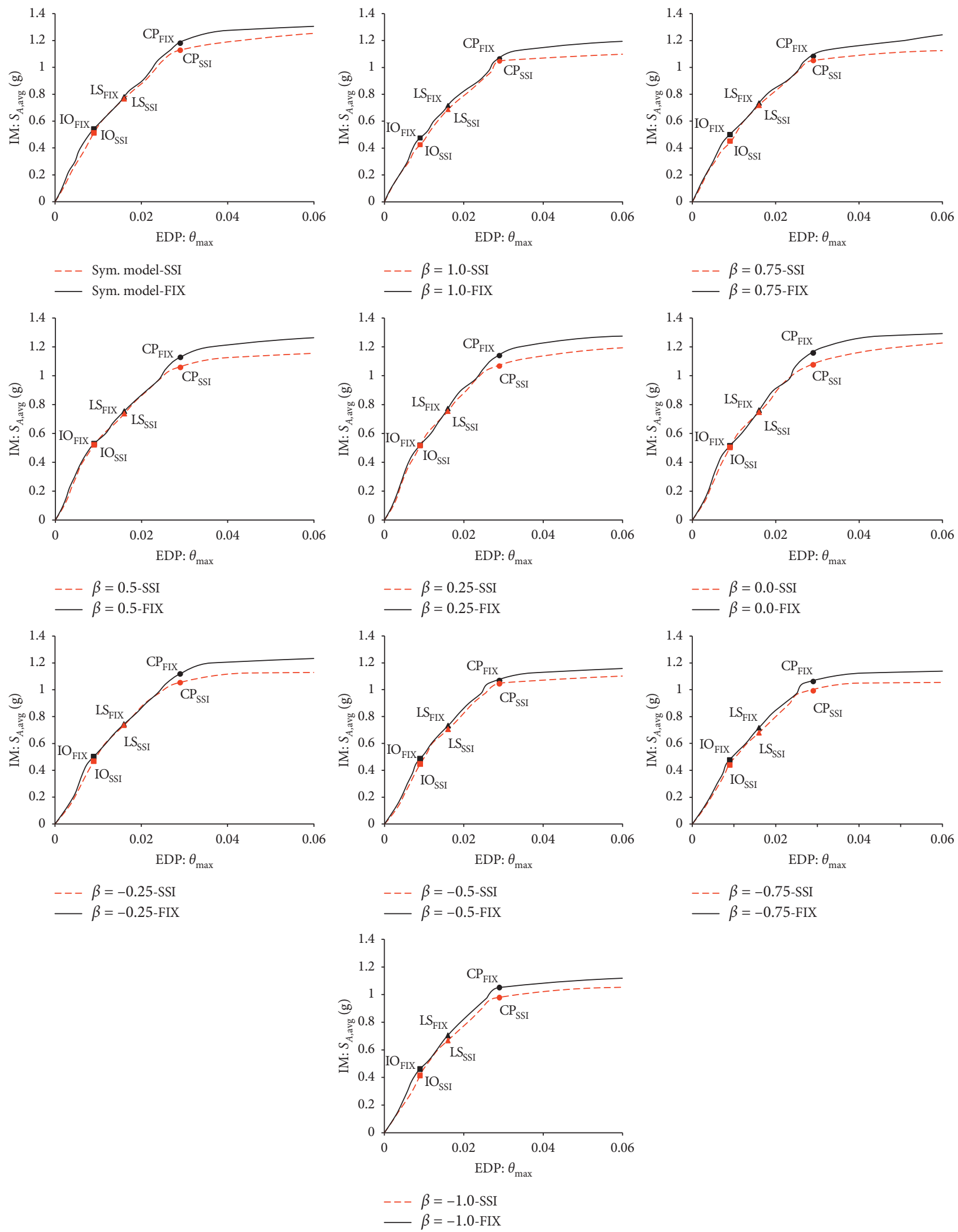

Figure 11: The median IDA curve of various models with fixed base and flexible base.

seen that for the IO and LS performance levels, the smallest MAFs belong to the asymmetric models with $\beta=0.5$ and 0.25 , respectively. As mentioned before, these models have balanced and near balanced configurations of CS and CR, respectively. However, for the $\mathrm{CP}$ performance level, the 


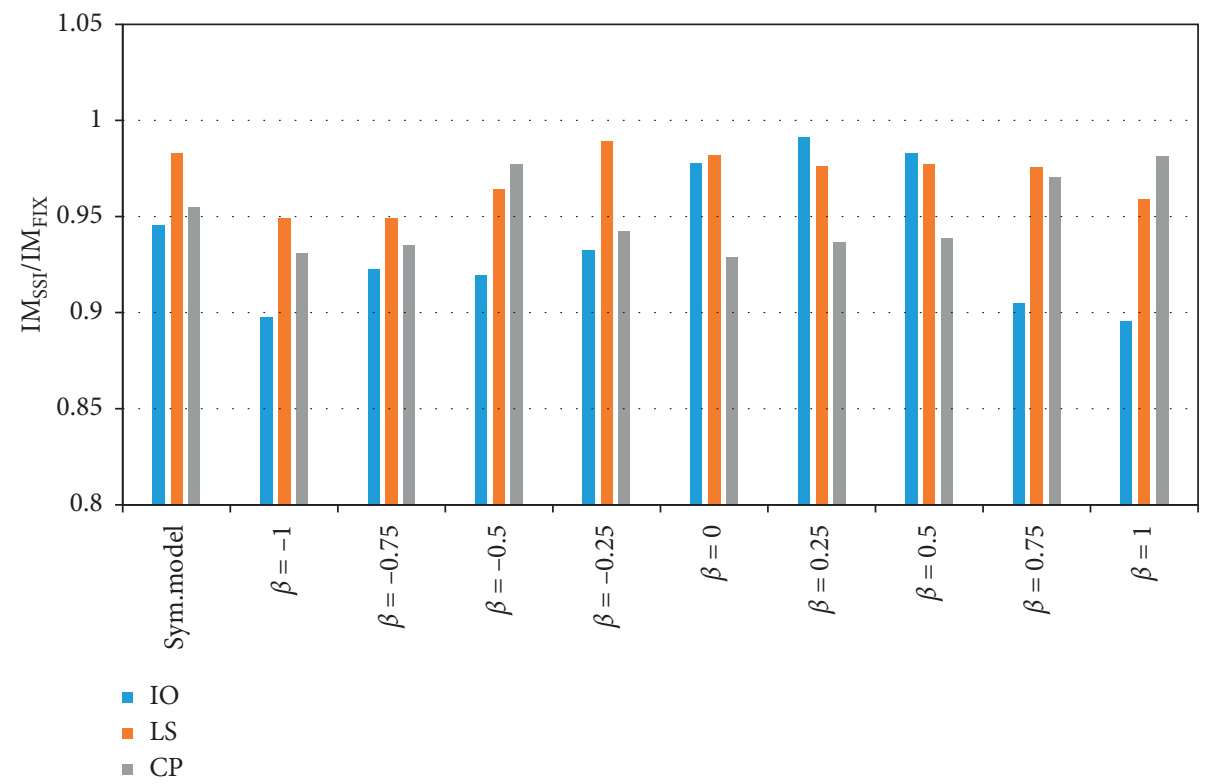

Figure 12: Comparison of the IM capacities of fixed- and flexible-base models.

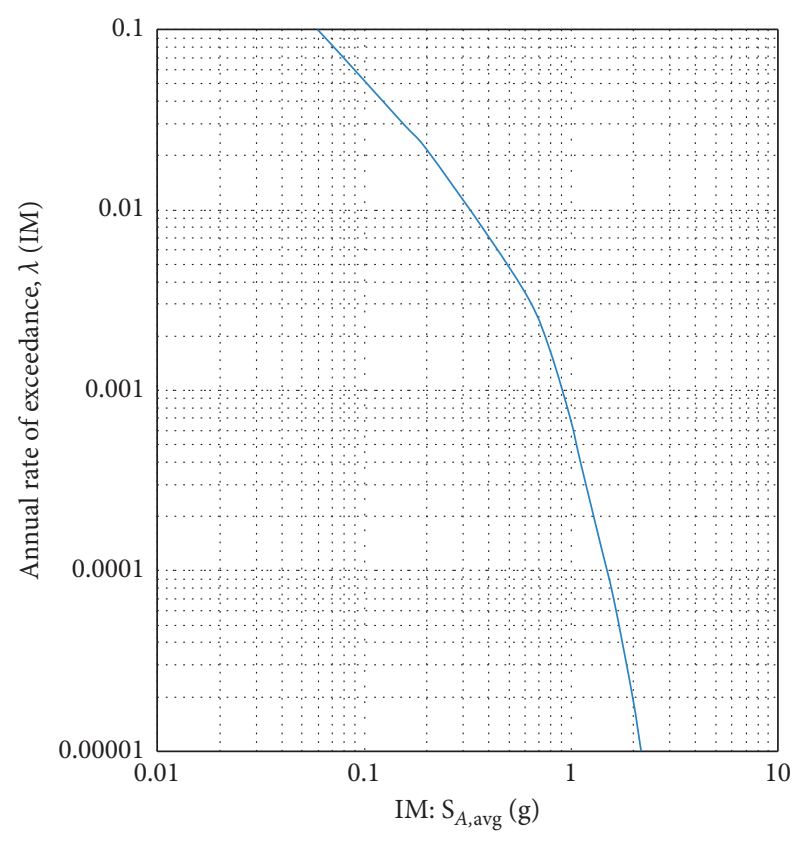

FIgURE 13: The seismic hazard curve used in this study.

asymmetric model with zero strength eccentricity $(\beta=0.0)$ has the smallest MAF value, and its behavior is closer to the symmetric model. It is notable that with regard to optimum strength distributions, the trends of the strength distribution effect are similar for both cases of fixed- and flexible-base conditions, and the same results are obtained from both conditions.

The ratio of the MAFs of the flexible-base models to the fixed-base ones is shown in Figure 16. It is apparent that the flexible effect of soil significantly increases the MAF values of the models in most cases. The highest rate of increase is observed for the CP performance level within the range of $10 \%$ to $45 \%$. However, the increase is reduced to up to $20 \%$ for the IO and LS performance levels.

5.3. The Confidence Level of Meeting the Performance Levels. In a probabilistic performance evaluation format, it is possible to examine the building performance by estimating a level of confidence of the building about the desired performance objective being met [68]. This format takes into account the randomness and uncertainty due to the seismic hazard and the structural capacity in the analysis. According to the following equations, the confidence level for satisfying a specific performance objective (CL) can be evaluated based on the standard Gaussian approach:

$$
\begin{aligned}
\mathrm{CL} & =\Phi\left(-\frac{1}{\beta_{U T}} \ln \left(\frac{\gamma_{R} D}{\phi_{R} C}\right)\right) \\
\beta_{U T} & =\sqrt{\beta_{U D}^{2}+\beta_{U C}^{2}} \\
\gamma_{R} & =e^{\left((k / 2 b) \beta_{R D}^{2}\right)} \\
\phi_{R} & =e^{\left(-(k / 2 b) \beta_{R C}^{2}\right)}
\end{aligned}
$$

where $C$ and $D$ are the median drift capacity and median drift demand, respectively, which can be derived from the IDA method. $\phi_{R}$ and $\gamma_{R}$ are the factors that characterize the randomness in the prediction of the capacity and demand, respectively. Additionally, $\beta_{U T}$ is defined as the dispersion parameter which considers the epistemic uncertainty in the estimation of demand and capacity, and $\beta_{R D}$ and $\beta_{R C}$ are the standard deviation of the natural logarithmic of the drift capacity and demand, respectively. Finally, $b$ is a parameter 


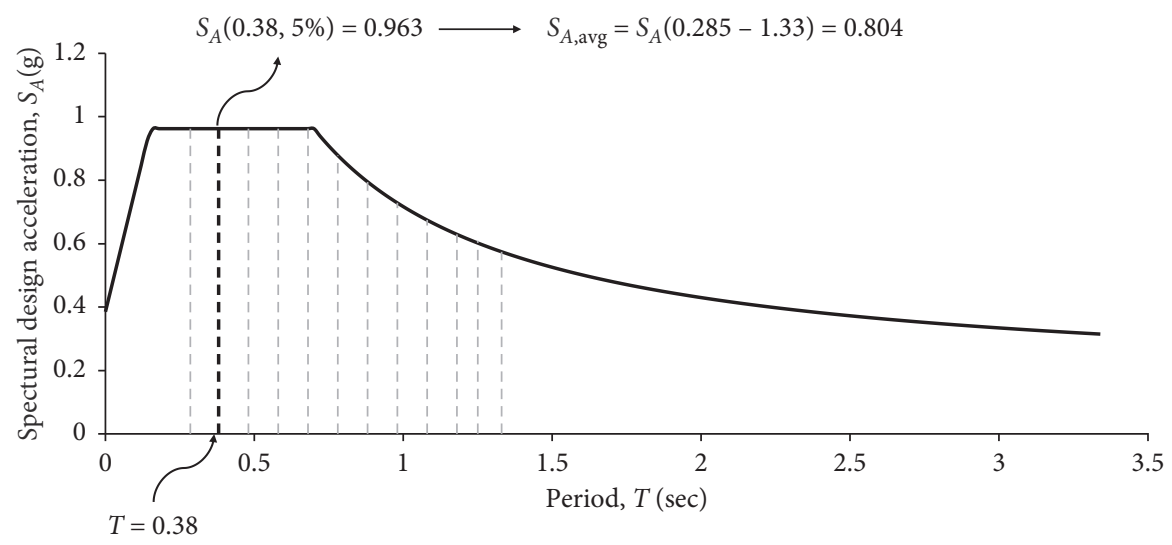

FIGURE 14: The standard design response spectrum of the considered site.

TABLE 11: The mean annual frequency of exceeding the IO, LS, and CP performance levels of structures with fixed base.

\begin{tabular}{lcccccccccc}
\hline Model no. & $\beta$ & \multicolumn{3}{c}{$\mathrm{IO}$} & & & $\mathrm{LS}$ & & \multicolumn{2}{c}{$\mathrm{CP}$} \\
& & $\mathrm{IM}^{c}(\mathrm{~g})$ & $\lambda_{P L}$ & $T$ (year) & $\mathrm{IM}^{c}(\mathrm{~g})$ & $\lambda_{P L}$ & $T$ (year) & $\mathrm{IM}^{c}(\mathrm{~g})$ & $\lambda_{P L}$ & $T(\mathrm{year})$ \\
\hline 1 & Sym. model & 0.541 & 0.0043 & 230 & 0.779 & 0.0021 & 487 & 1.181 & 0.00065 & 1532 \\
2 & -1.0 & 0.461 & 0.0061 & 163 & 0.704 & 0.0028 & 361 & 1.051 & 0.00120 & 833 \\
3 & -0.75 & 0.477 & 0.0058 & 174 & 0.717 & 0.0026 & 384 & 1.061 & 0.00113 & 887 \\
4 & -0.5 & 0.486 & 0.0056 & 179 & 0.732 & 0.0025 & 393 & 1.068 & 0.00090 & 1113 \\
5 & -0.25 & 0.502 & 0.0053 & 189 & 0.744 & 0.0024 & 412 & 1.117 & 0.00087 & 1153 \\
6 & 0.0 & 0.513 & 0.0050 & 201 & 0.760 & 0.0022 & 465 & 1.158 & 0.00074 & 1349 \\
7 & 0.25 & 0.520 & 0.0047 & 213 & 0.773 & 0.0021 & 488 & 1.140 & 0.00078 & 1279 \\
8 & 0.5 & 0.530 & 0.0046 & 217 & 0.755 & 0.0022 & 459 & 1.127 & 0.00095 & 1056 \\
9 & 0.75 & 0.500 & 0.0053 & 188 & 0.736 & 0.0024 & 417 & 1.083 & 0.00103 & 971 \\
10 & 1.0 & 0.475 & 0.0058 & 173 & 0.716 & 0.0025 & 396 & 1.065 & 0.00103 & 971 \\
\hline
\end{tabular}

TABLE 12: The mean annual frequency of exceeding the IO, LS, and CP performance levels of structures with flexible base.

\begin{tabular}{|c|c|c|c|c|c|c|c|c|c|c|}
\hline \multirow{2}{*}{ Model no. } & \multirow{2}{*}{$\beta$} & \multicolumn{3}{|c|}{ IO } & \multicolumn{3}{|c|}{ LS } & \multicolumn{3}{|c|}{$\mathrm{CP}$} \\
\hline & & $\mathrm{IM}^{\widehat{c}}(\mathrm{~g})$ & $\lambda_{P L}$ & $T$ (year) & $\operatorname{IM}^{\widehat{c}}(\mathrm{~g})$ & $\lambda_{P L}$ & $T$ (year) & $\operatorname{IM}^{\widehat{c}}(\mathrm{~g})$ & $\lambda_{P L}$ & $T$ (year) \\
\hline 1 & Sym. model & 0.512 & 0.0048 & 207 & 0.766 & 0.0021 & 474 & 1.127 & 0.00075 & 1340 \\
\hline 2 & -1.0 & 0.414 & 0.0072 & 138 & 0.668 & 0.0034 & 296 & 0.978 & 0.00160 & 626 \\
\hline 3 & -0.75 & 0.440 & 0.0065 & 153 & 0.680 & 0.0032 & 312 & 0.992 & 0.00147 & 678 \\
\hline 4 & -0.5 & 0.447 & 0.0064 & 155 & 0.706 & 0.0028 & 356 & 1.043 & 0.00118 & 848 \\
\hline 5 & -0.25 & 0.468 & 0.0061 & 165 & 0.736 & 0.0025 & 405 & 1.053 & 0.00118 & 847 \\
\hline 6 & 0.0 & 0.502 & 0.0051 & 197 & 0.747 & 0.0022 & 448 & 1.076 & 0.00101 & 994 \\
\hline 7 & 0.25 & 0.515 & 0.0047 & 211 & 0.754 & 0.0022 & 460 & 1.067 & 0.00114 & 875 \\
\hline 8 & 0.5 & 0.521 & 0.0047 & 213 & 0.738 & 0.0025 & 407 & 1.058 & 0.00122 & 822 \\
\hline 9 & 0.75 & 0.452 & 0.0064 & 155 & 0.718 & 0.0027 & 368 & 1.051 & 0.00114 & 877 \\
\hline 10 & 1.0 & 0.425 & 0.0070 & 143 & 0.686 & 0.0030 & 334 & 1.045 & 0.00114 & 876 \\
\hline
\end{tabular}

that reflects the power-law relationship between $\theta_{\max }$ demand and IM.

In this section, the confidence levels for meeting the performance levels are investigated for both the fixed- and flexible-base structural models. For this purpose, the confidence levels for satisfying the performance levels are calculated for different intensity levels $\left(S_{A, \text { avg }} s\right)$ (see Figures 17 and 18). It can be observed that in many cases in both the fixed-and flexible-base conditions, the symmetric model has higher confidence levels than the asymmetric models. For the IO and LS performance levels, the asymmetric model with $\beta=-1.0$ (with maximum stiffness eccentricity) has the lowest confidence levels. However, for the CP performance level, the lowest confidence is achieved in the asymmetric model with $\beta=1.0$ (with maximum strength eccentricity and zero stiffness eccentricity).

For a more complete comparison, the IM capacities corresponding to $70 \%$ confidence in satisfying each limit state are extracted from the figures and shown in Table 13. The higher IM values, highlighted in the table, reflect better 


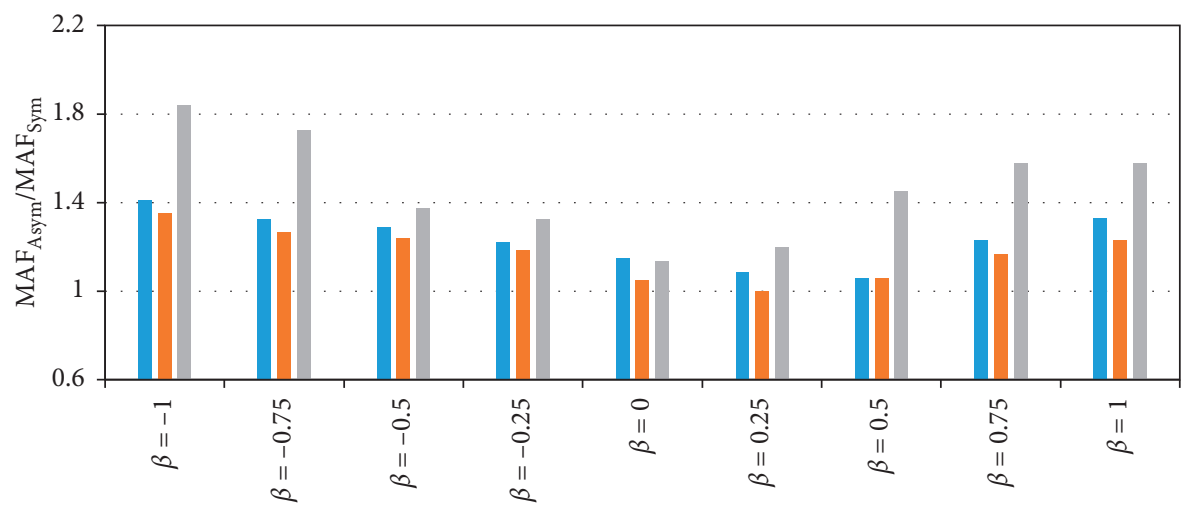

- IO

- LS

- $\mathrm{CP}$

(a)

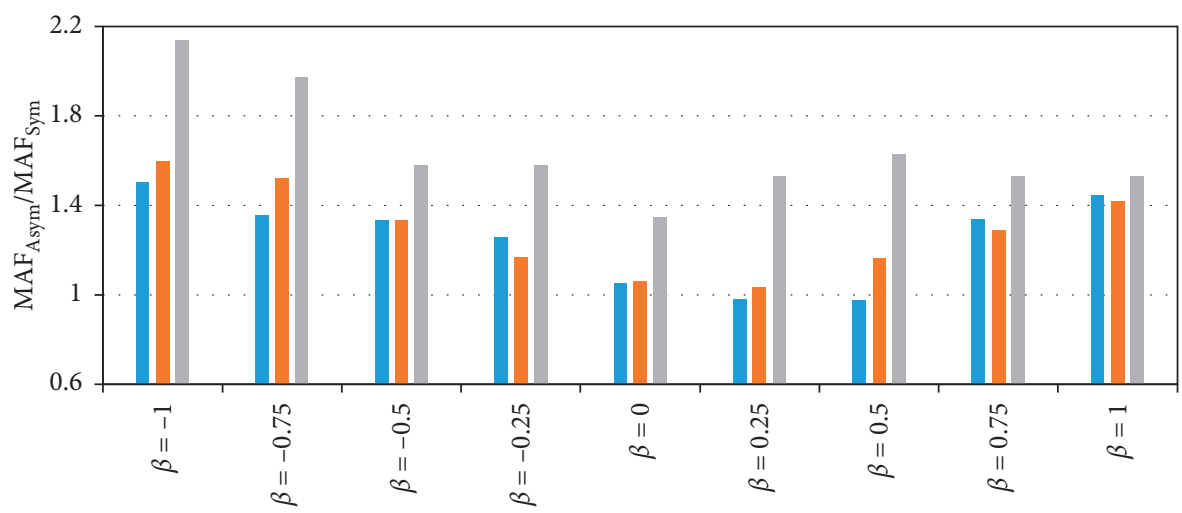

- IO

- LS

- $\mathrm{CP}$

(b)

Figure 15: Comparison of the MAFs of the asymmetric models to the symmetric model: (a) fixed base; (b) flexible base.

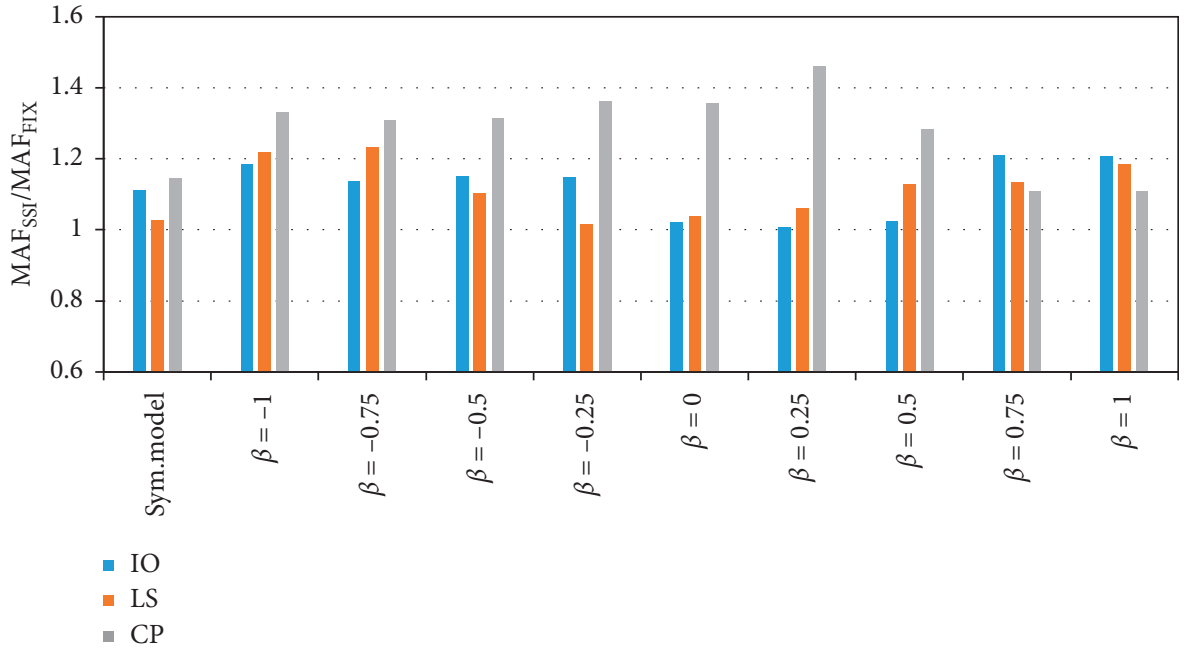

FIgUre 16: Comparison of the MAFs of fixed- and flexible-base models. 

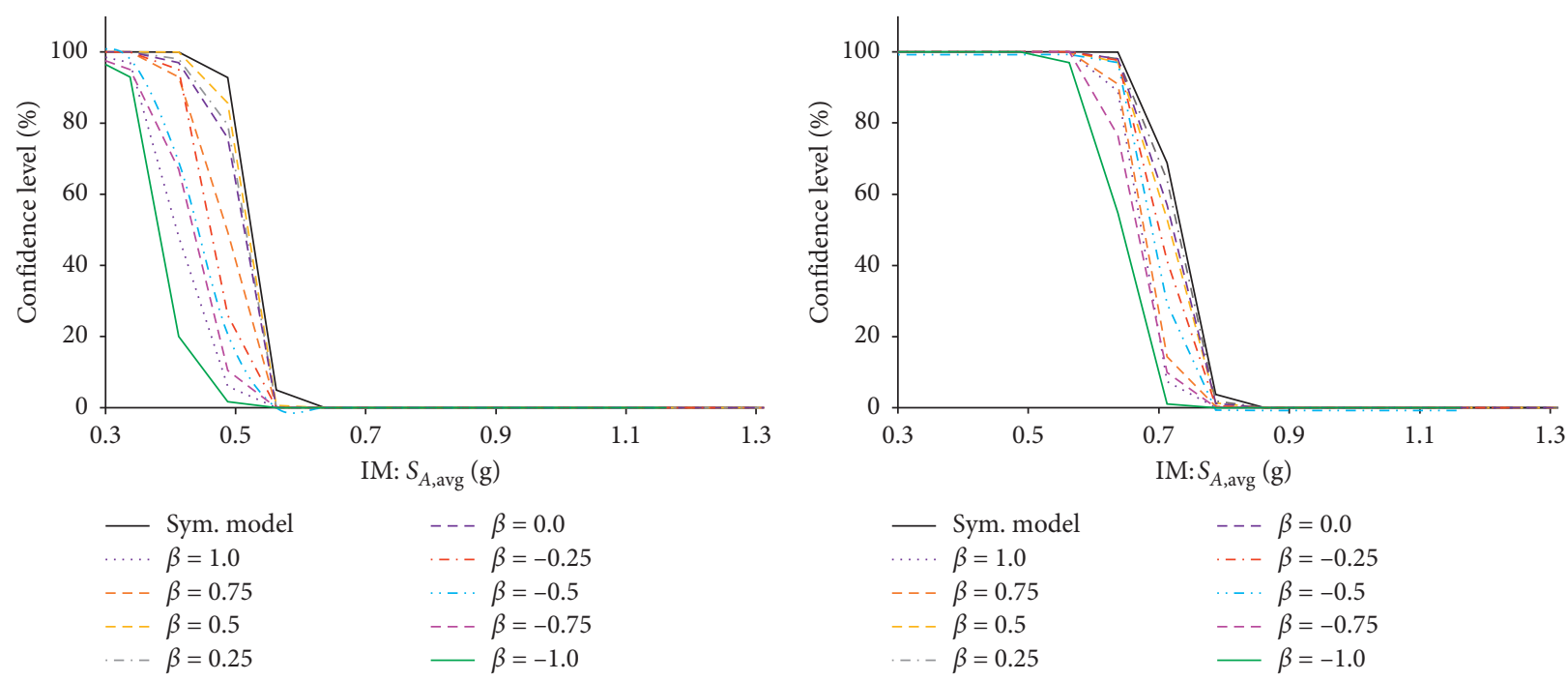

(a)

(b)

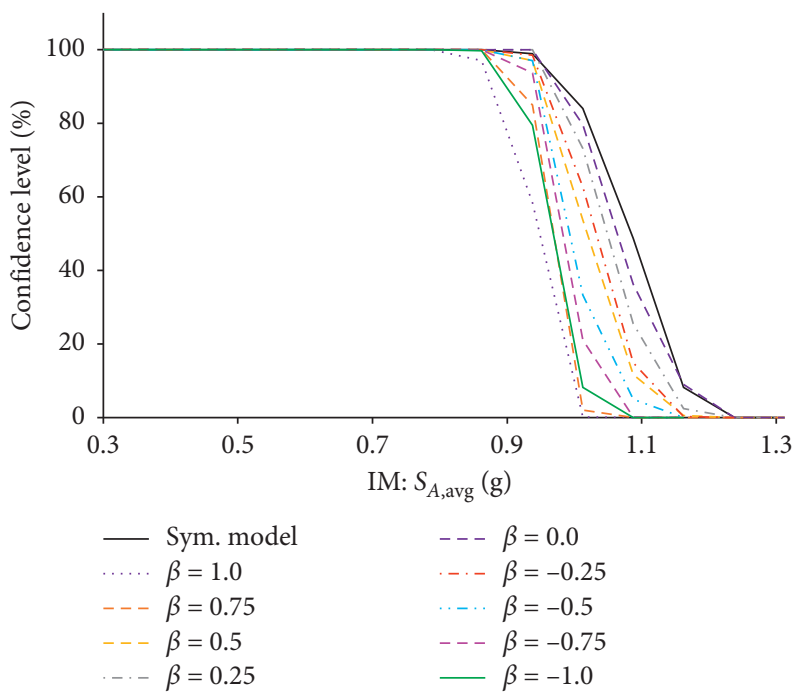

(c)

Figure 17: Confidence levels for models with fixed base: (a) IO, (b) LS, and (c) CP.
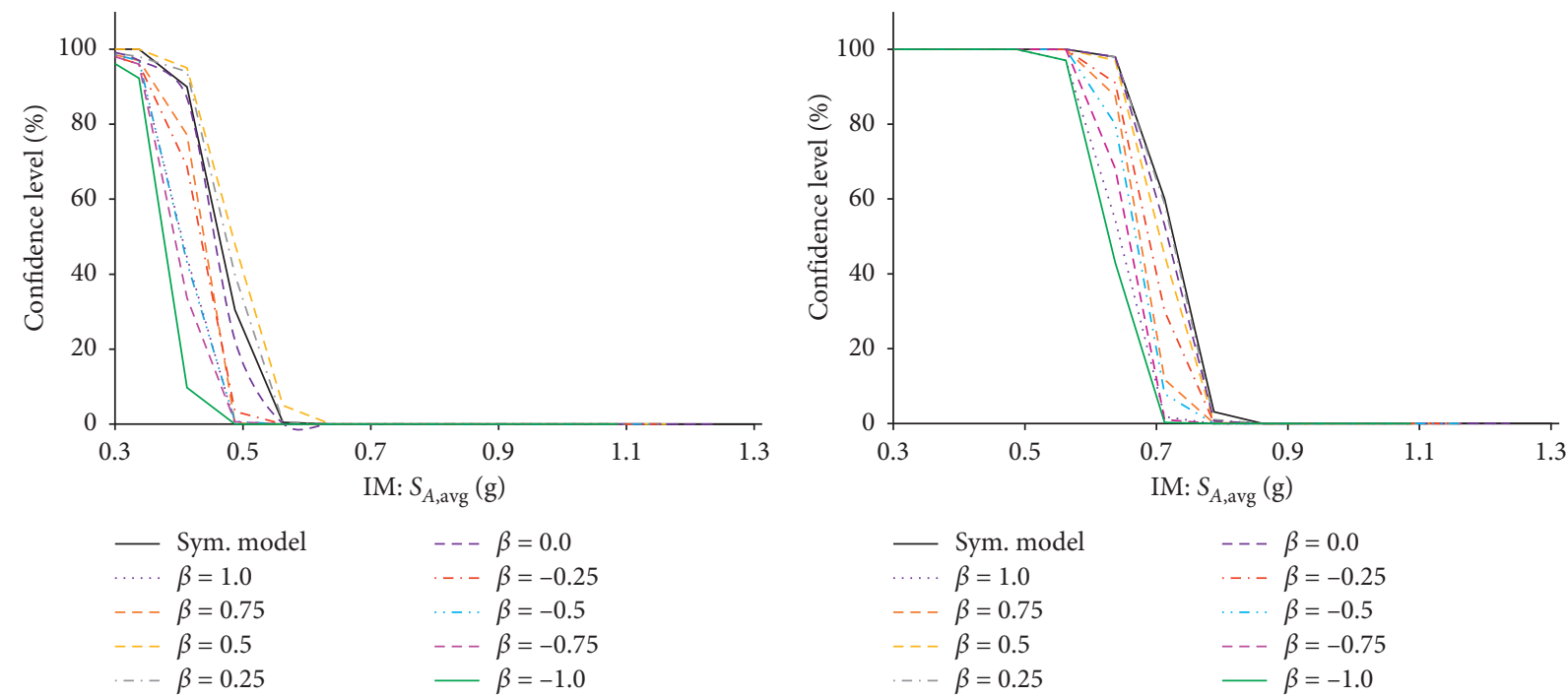

(a)

(b)

Figure 18: Continued. 


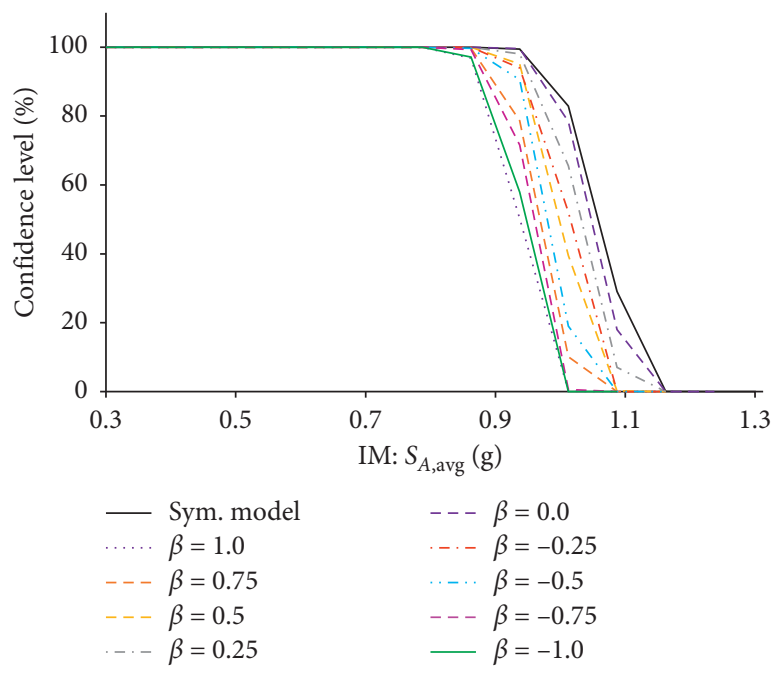

(c)

FIGURE 18: Confidence levels for models with flexible base: (a) IO, (b) LS, and (c) CP.

TABLE 13: IM capacities corresponding to $C L=70 \%$ in the models with fixed and flexible base.

\begin{tabular}{|c|c|c|c|c|c|c|c|}
\hline \multirow{2}{*}{ Model no. } & \multirow{2}{*}{$\beta$} & \multicolumn{3}{|c|}{ Fixed base } & \multicolumn{3}{|c|}{ Flexible base } \\
\hline & & $\mathrm{IO}$ & LS & $\mathrm{CP}$ & $\mathrm{IO}$ & LS & $\mathrm{CP}$ \\
\hline 1 & Sym. model & 0.507 & 0.710 & 1.042 & 0.437 & 0.693 & 1.030 \\
\hline 2 & -1.0 & 0.361 & 0.610 & 0.947 & 0.358 & 0.600 & 0.914 \\
\hline 3 & -0.75 & 0.405 & 0.645 & 0.962 & 0.369 & 0.633 & 0.939 \\
\hline 4 & -0.5 & 0.410 & 0.668 & 0.969 & 0.375 & 0.648 & 0.959 \\
\hline 5 & -0.25 & 0.440 & 0.674 & 0.997 & 0.409 & 0.663 & 0.981 \\
\hline 6 & 0.0 & 0.493 & 0.689 & 1.029 & 0.432 & 0.684 & 1.023 \\
\hline 7 & 0.25 & 0.496 & 0.699 & 1.017 & 0.446 & 0.691 & 1.002 \\
\hline 8 & 0.5 & 0.501 & 0.684 & 0.984 & 0.452 & 0.676 & 0.971 \\
\hline 9 & 0.75 & 0.452 & 0.658 & 0.951 & 0.419 & 0.655 & 0.947 \\
\hline 10 & 1.0 & 0.379 & 0.655 & 0.915 & 0.375 & 0.610 & 0.906 \\
\hline
\end{tabular}

probabilistic performance. Similar to what was seen in the previous section for the MAF values, for both the fixed- and flexible-base conditions, the asymmetric models with $\beta=0.5$ and 0.25 have the best performance in the IO and LS limit state, respectively, but for the CP limit sate, the asymmetric model with no strength eccentricity $(\beta=0.0)$ performs better. Furthermore, except for the models with $\beta=0.5$ and 0.25 , the IM capacities of the asymmetric models corresponding to $\mathrm{CL}=70 \%$ are reduced by 2 to $30 \%$ relative to that of the symmetric model. It is also observed that the IM capacities of the flexible-base models corresponding to $\mathrm{CL}=70 \%$ are decreased by up to $15 \%$ in comparison with those of the fixed-base models.

\section{Conclusion}

This study used the incremental dynamic analysis (IDA) method to investigate the effect of different strength distributions on the seismic performance of single-story planasymmetric reinforced concrete buildings with wall-frame systems in the framework of probabilistic-based earthquake engineering. Two different base conditions (fixed and flexible) were considered for the structural models, and an attempt was made to find the most efficient strength distribution for meeting each performance level in each base condition. Firstly, an optimal intensity measure (IM) was selected for the structures. Then, the interstory drift capacities of the structures for three common performance levels (immediate occupancy, life safety, and collapse prevention) were estimated using the damage index concept. Finally, the probabilistic performance of the structural models was evaluated in terms of the mean annual frequency of exceeding different performance limit states and their confidence level. The following main conclusions were drawn:

(1) According to the result derived from the investigation of efficiency and sufficiency of 30 candidate IMs, the average $S_{A}\left(0.75 T_{1}-3.5 T_{1}\right)$ was selected as the optimal IM for the considered structural models.

(2) The interstory drift ratios of $0.9 \%, 1.6 \%$, and $2.9 \%$ were estimated as the appropriate IO, LS, and CP limit-state capacities, respectively, for the wall-frame structural models of this study.

(3) The nonuniform distribution of strength and stiffness properties in the plan has remarkable effects on 
the seismic performance of the buildings, and by using an appropriate strength distribution, the negative effects of plan-asymmetry can be reduced.

(4) The optimum strength distribution is a function of the performance level objective. In the IO performance level, a desirable strength distribution is the one which results in a balanced configuration of the centers of stiffness and strength, where the eccentricities of both parameters are almost equal $(\beta=0.5)$. In the LS performance level, the best probabilistic performance could be achieved in the asymmetric model with a nearly balanced configuration $(\beta=0.25)$ in which the strength eccentricity is smaller than the stiffness eccentricity. However, in the CP performance level, the asymmetric model with zero strength eccentricity $(\beta=0.0)$ performs better. These optimum strength distributions can be adopted in the performancebased design of asymmetric buildings.

(5) The lowest confidence levels of meeting performance levels were observed in the asymmetric models with $\beta=-1.0$ and -0.75 (with the center of stiffness being on the same side as the center of strength) and $\beta=1.0$ and 0.75 (having zero or almost zero stiffness eccentricity).

(6) Soil-structure interaction effect reduces the IM capacities corresponding to a given confidence level in meeting performance objectives. This implies that ignoring the effect of soil flexibility in the design practice of the asymmetric buildings can result in overestimating the seismic capacity, and this phenomenon should be taken into consideration in the design of this type of buildings.

(7) The introduction of soil flexibility in the models increases the mean annual frequency of exceedance of the performance levels. The maximum rate of increase is about $20 \%$ for the IO and LS performance levels. However, this rate is observed within the range of $10 \%$ to $45 \%$ for the CP performance level.

(8) The effect of soil flexibility does not influence the optimum strength distributions for improving the seismic performance of wall-frame asymmetric models, and the optimum configurations are the same for the structures with fixed and flexible base.

\section{Data Availability}

The data used during the study are included in the submitted article, and the software codes used to support the findings are available from the corresponding author upon request.

\section{Conflicts of Interest}

The authors declare that they have no conflicts of interest.

\section{Acknowledgments}

The authors wish to express their sincere gratitude to Professor Ghyslaine McClure from McGill University for her valuable and constructive comments which remarkably improved the article. Her willingness to give her time so generously has been very much appreciated.

\section{References}

[1] T. Paulay and M. J. N. Priestley, Seismic Design of Reinforced Concrete and Masonry Buildings, John Wiley \& Sons, New York, NY, USA, 1992.

[2] M. N. Fardis, Advances in Performance-Based Earthquake Engineering (ACES Workshop), Springer, Dordrecht, Netherlands, 2010.

[3] T. Paulay, "Some design principles relevant to torsional phenomena in ductile buildings," Journal of Earthquake Engineering, vol. 5, no. 3, pp. 273-308, 2001.

[4] M. Aschheim, "Seismic design based on the yield displacement," Earthquake Spectra, vol. 18, no. 4, pp. 581-600, 2002.

[5] M. J. N. Priestley, G. M. Calvi, and M. J. Kowalsky, Displacement-Based Seismic Design of Structures, IUSS Press, Pavia, Italy, 2007.

[6] W. K. Tso and H. Ying, "Lateral strength distribution specification to limit additional inelastic deformation of torsionally unbalanced structures," Engineering Structures, vol. 14, no. 4, pp. 263-277, 1992.

[7] W. K. Tso and R. S. H. Smith, "Re-evaluation of seismic torsional provisions," Earthquake Engineering \& Structural Dynamics, vol. 28, no. 8, pp. 899-917, 1999.

[8] T. Paulay, "Seismic torsional effects on ductile structural wall systems," Journal of Earthquake Engineering, vol. 1, no. 4, pp. 721-745, 1997.

[9] W. K. Tso and B. Myslimaj, "A yield displacement distribution-based approach for strength assignment to lateral forceresisting elements having strength dependent stiffness," Earthquake Engineering \& Structural Dynamics, vol. 32, no. 15, pp. 2319-2351, 2003.

[10] B. Myslimaj and W. K. Tso, "A design-oriented approach to strength distribution in single-story asymmetric systems with elements having strength-dependent stiffness," Earthquake Spectra, vol. 21, no. 1, pp. 197-212, 2005.

[11] H. Shakib and A. Ghasemi, "Considering different criteria for minimizing torsional response of asymmetric structures under near-fault and far-fault excitations," International Journal of Civil Engineering, vol. 5, no. 4, pp. 247-265, 2007.

[12] A. Aziminejad and A. S. Moghadam, "Performance of asymmetric multi-story shear buildings with different strength distributions," Journal of Applied Sciences, vol. 6, no. 9, pp. 1082-1089, 2009.

[13] A. Aziminejad and A. S. Moghadam, "Fragility-based performance evaluation of asymmetric single-story buildings in near field and far field earthquakes," Journal of Earthquake Engineering, vol. 14, no. 6, pp. 789-816, 2010.

[14] T. Balendra, C. W. Tat, and S.-L. Lee, "Modal damping for torsionally coupled buildings on elastic foundation," Earthquake Engineering \& Structural Dynamics, vol. 10, no. 5, pp. 735-756, 1982.

[15] K. S. Sivakumaran and T. Balendra, "Seismic analysis of asymmetric multistorey buildings including foundation interaction and P- $\Delta$ effects," Engineering Structures, vol. 16, no. 8, pp. 609-624, 1994.

[16] W.-H. Wu, J.-F. Wang, and C.-C. Lin, "Systematic assessment of irregular building-soil interaction using efficient modal analysis," Earthquake Engineering \& Structural Dynamics, vol. 30, no. 4, pp. 573-594, 2001. 
[17] H. Shakib and A. Fuladgar, "Dynamic soil-structure interaction effects on the seismic response of asymmetric buildings," Soil Dynamics and Earthquake Engineering, vol. 24, no. 5, pp. 379-388, 2004.

[18] R. Roy and S. Chandra Dutta, "Inelastic seismic demand of low-rise buildings with soil-flexibility," International Journal of Non-linear Mechanics, vol. 45, no. 4, pp. 419-432, 2010.

[19] H. Shakib and G. Atefatdoost, "Minimizing the torsional response of asymmetric wall-type systems considering soilstructure interaction," International Journal of Civil Engineering, vol. 12, no. 1A, pp. 14-24, 2014.

[20] G. R. Atefatdoost, B. JavidSharifi, and H. Shakib, "Effects of foundation flexibility on seismic demands of asymmetric buildings subject to near-fault ground motions," Structural Engineering and Mechanics, vol. 66, no. 5, pp. 637-648, 2018.

[21] T. Paulay, "An estimation of displacement limits for ductile systems," Earthquake Engineering \& Structural Dynamics, vol. 31, no. 3, pp. 583-599, 2002.

[22] Building and Housing Research Centre, Iranian Code of Practice for Seismic Resistant Design of Buildings (Standard 2800), Building and Housing Research Centre, Tehran, Iran, 4th edition, 2014.

[23] Pacific Earthquake Engineering Research Center, Open System for Earthquake Engineering Simulation OpenSees, V.2.5.2, Pacific Earthquake Engineering Research Center, Berkeley, CA, USA, 2017.

[24] A. K. Chopra, Dynamics of Structures: Theory and Applications to Earthquake Engineering, Prentice-Hall, Englewood Cliffs, NJ, USA, 2007.

[25] L. F. Ibarra, R. A. Medina, and H. Krawinkler, "Hysteretic models that incorporate strength and stiffness deterioration," Earthquake Engineering \& Structural Dynamics, vol. 34, no. 12, pp. 1489-1511, 2005.

[26] H. Krawinkler and F. Zareian, "Prediction of collapse-how realistic and practical is it, and what can we learn from it?" The Structural Design of Tall and Special BuildingsE, vol. 16, no. 5, pp. 633-653, 2007.

[27] American Society of Civil Engineers, Seismic Evaluation and Retrofit of Existing Buildings (ASCE/SEI 41-13), American Society of Civil Engineers, Reston, VA, USA, 2013.

[28] Institute of Building National Code, Iranian National Building Code, Part 7-Foundation Design, Institute of Building National Code, Tehran, Iran, 2014.

[29] F. Behnamfar and M. Banizadeh, "Effects of soil-structure interaction on distribution of seismic vulnerability in RC structures," Soil Dynamics and Earthquake Engineering, vol. 80, pp. 73-86, 2016.

[30] S. Gajan, T. Hutchinson, B. L. Kutter, P. Raychowdhury, and A. Ugalde, "Numerical models for analysis and performancebased design of shallow foundations subjected to seismic loading," Technical Report 2007/04, Pacific Earthquake Engineering Research Center (PEER), University of California, Berkeley, CA, USA, 2007.

[31] P. Raychowdhury and T. Hutchinson, "Nonlinear material models for Winkler-based shallow foundation response evaluation," in Proceedings of the Geo Congress, New Orleans, LA, USA, March 2008.

[32] C. W. Harden, T. C. Hutchinson, G. R. Martin, and B. L. Kutter, "Numerical modeling of the nonlinear cyclic response of shallow foundations," Technical Report 2005/04, Pacific Earthquake Engineering Research Center (PEER), University of California, Berkeley, CA, USA, 2005.

[33] P. Raychowdhury, "Seismic response of low-rise steel moment-resisting frame (SMRF) buildings incorporating nonlinear soil-structure interaction (SSI)," Engineering Structures, vol. 33, no. 3, pp. 958-967, 2011.

[34] M. A. Ghannad and A. H. Jafarieh, "Inelastic displacement ratios for soil-structure systems allowed to uplift," Earthquake Engineering \& Structural Dynamics, vol. 43, no. 9, pp. 14011421, 2014.

[35] H. Masaeli, F. Khoshnoudian, and R. Ziaei, "Rocking soilstructure systems subjected to near-fault pulses," Journal of Earthquake Engineering, vol. 19, no. 3, pp. 461-479, 2015.

[36] P. Raychowdhury and S. Ray-Chaudhuri, "Seismic response of nonstructural components supported by a 4-story SMRF: effect of nonlinear soil-structure interaction," Structures, vol. 3, pp. 200-210, 2015.

[37] H. Shakib and F. Homaei, "Probabilistic seismic performance assessment of the soil-structure interaction effect on seismic response of mid-rise setback steel buildings," Bulletin of Earthquake Engineering, vol. 15, no. 7, pp. 2827-2851, 2017.

[38] R. W. Boulanger, C. J. Curras, B. L. Kutter, D. W. Wilson, and A. Abghari, "Seismic soil-pile-structure interaction experiments and analyses," Journal of Geotechnical and Geoenvironmental Engineering, vol. 125, no. 9, pp. 750-759, 1999.

[39] https://ngawest2.berkeley.edu/.

[40] D. Vamvatsikos and C. A. Cornell, "Incremental dynamic analysis," Earthquake Engineering \& Structural Dynamics, vol. 31, no. 3, pp. 491-514, 2002.

[41] FEMA, "Recommended seismic design criteria for new steel moment frame buildings," Report No. FEMA-350, Washington, DC, USA, 2000.

[42] FEMA, "Prestandard and commentary for the seismic rehabilitation of buildings," Report No. FEMA-356, Washington, DC, USA, 2000.

[43] FEMA, "Quantification of building seismic performance factors," Report No. FEMA-P695, Washington, DC, USA, 2009.

[44] N. Luco and C. A. Cornell, "Structure-specific scalar intensity measures for near-source and ordinary earthquake ground motions," Earthquake Spectra, vol. 23, no. 2, pp. 357-392, 2007.

[45] A. Elenas and K. Meskouris, "Correlation study between seismic acceleration parameters and damage indices of structures," Engineering Structures, vol. 23, no. 6, pp. 698-704, 2001.

[46] S. Akkar and B. Küçükdoğan, "Direct use of PGV for estimating peak nonlinear oscillator displacements," Earthquake Engineering \& Structural Dynamics, vol. 37, no. 12, pp. 1411-1433, 2008.

[47] N. Shome, C. A. Cornell, P. Bazzurro, and J. E. Carballo, "Earthquakes, records, and nonlinear responses," Earthquake Spectra, vol. 14, no. 3, pp. 469-500, 1998.

[48] P. Giovenale, C. A. Cornell, and L. Esteva, "Comparing the adequacy of alternative ground motion intensity measures for the estimation of structural responses," Earthquake Engineering \& Structural Dynamics, vol. 33, no. 8, pp. 951-979, 2004.

[49] P. P. Cordova, G. G. Deierlein, S. S. F. Mehanny, and C. A. Cornell, "Development of a two parameter seismic intensity measure and probabilistic assessment procedure," in Proceedings of the 2nd US-Japan Workshop on PerformanceBased Earthquake Engineering Methodology for RC Building Structures, Sapporo, Japan, September 2000.

[50] D. Vamvatsikos and C. A. Cornell, "Developing efficient scalar and vector intensity measures for IDA capacity estimation by incorporating elastic spectral shape information," Earthquake Engineering \& Structural Dynamics, vol. 34, no. 13, pp. 1573-1600, 2005. 
[51] A. K. Kazantzi and D. Vamvatsikos, "Intensity measure selection for vulnerability studies of building classes," Earthquake Engineering \& Structural Dynamics, vol. 44, no. 15, pp. 2677-2694, 2015.

[52] S. Tsantaki, C. Adam, and L. F. Ibarra, "Intensity measures that reduce collapse capacity dispersion of P-delta vulnerable simple systems," Bulletin of Earthquake Engineering, vol. 15, no. 3, pp. 1085-1109, 2017.

[53] M. Kohrangi, P. Bazzurro, and D. Vamvatsikos, "Vector and scalar IMs in structural response estimation, part I: hazard analysis," Earthquake Spectra, vol. 32, no. 3, pp. 1507-1524, 2016.

[54] M. Kohrangi, P. Bazzurro, and D. Vamvatsikos, "Vector and scalar IMs in structural response estimation, part II: building demand assessment," Earthquake Spectra, vol. 32, no. 3, pp. 1525-1543, 2016.

[55] M. Bianchini, P. P. Diotallevi, and J. W. Baker, "Prediction of inelastic structural response using an average of spectral accelerations," in Proceedings of the 10th International Conference on Structural Safety and Reliability, Osaka, Japan, September 2009.

[56] M. Pirizadeh and H. Shakib, "Evaluation of efficient ground motion intensity measure for vertical irregular structures by aims of reducing the dependency of results to record selection," in Proceedings of the 6th International Conference on Seismology and Earthquake Engineering, Tehran, Iran, May 2011.

[57] L. Eads, E. Miranda, and D. G. Lignos, "Average spectral acceleration as an intensity measure for collapse risk assessment," Earthquake Engineering \& Structural Dynamics, vol. 44, no. 12, pp. 2057-2073, 2015.

[58] M. A. A. Al-Baadani and M. Al-Shameri, "Study of dispersion of the ground motion intensity measure of R/C frame minaret," MUST Journal of Engineering and Applied Sciences, vol. 1, no. 1, pp. 24-33, 2017.

[59] P. Colajanni, S. Pagnotta, and G. Testa, "Comparison of fully non-stationary artificial accelerogram generation methods in reproducing seismicity at a given site," Soil Dynamics and Earthquake Engineering, vol. 133, Article ID 106135, 2020.

[60] C. A. Cornell, F. Jalayer, R. O. Hamburger, and D. A. Foutch, "Probabilistic basis for 2000 SAC federal emergency management agency steel moment frame guidelines," Journal of Structural Engineering, vol. 128, no. 4, pp. 526-533, 2002.

[61] J. E. Padgett and R. DesRoches, "Methodology for the development of analytical fragility curves for retrofitted bridges," Earthquake Engineering and Structural Dynamics, vol. 37, no. 13, pp. 1157-1174, 2008.

[62] H. Shakib and V. Jahangiri, "Intensity measures for the assessment of the seismic response of buried steel pipelines," Bulletin of Earthquake Engineering, vol. 14, no. 4, pp. 12651284, 2016.

[63] S.-H. Jeong, A. M. Mwafy, and A. S. Elnashai, "Probabilistic seismic performance assessment of code-compliant multistory RC buildings," Engineering Structures, vol. 34, pp. 527-537, 2012.

[64] A. Ghobarah, N. M. Aly, and M. El-Attar, "Seismic reliability assessment of existing reinforced concrete buildings," Journal of Earthquake Engineering, vol. 2, no. 4, pp. 569-592, 1998.

[65] Y. J. Park and A. H. S. Ang, "Mechanistic seismic damage model for reinforced concrete," Journal of Structural Engineering, vol. 111, no. 4, pp. 722-739, 1985.

[66] S. K. Kunnath, A. M. Reinhorn, and R. F. Lobo, "IDARC version 3.0: a program for the inelastic damage analysis of reinforced concrete structures," State University of New York,
New York, NY, USA, NCEER-92-0022, National Center for Earthquake Engineering Research, 1992.

[67] P. Bazzurro and C. A. Cornell, "Seismic hazard analysis of nonlinear structures. I: methodology," Journal of Structural Engineering, vol. 120, no. 11, pp. 3320-3344, 1994.

[68] F. Jalayer and C. A. Cornell, "A technical framework for probability-based demand and capacity factor design (DCFD) seismic formats," University of California, Berkeley, CA, USA, PEER-2003/08, Pacific Earthquake Engineering Research Center, 2003.

[69] F. Jalayer and C. A. Cornell, “Alternative non-linear demand estimation methods for probability-based seismic assessments," Earthquake Engineering \& Structural Dynamics, vol. 38, no. 8, pp. 951-972, 2009.

[70] B. Asgarian, A. Sadrinezhad, and P. Alanjari, "Seismic performance evaluation of steel moment resisting frames through incremental dynamic analysis," Journal of Constructional Steel Research, vol. 66, no. 2, pp. 178-190, 2010.

[71] R. Medina, Seismic demands for non-deteriorating frame structures and their dependence on ground motions, Ph.D. thesis, Department of Civil and Environmental Engineering, Stanford, CA, USA, 2002. 